\title{
Monitoring and Mitigation Alternatives for Protection of North Atlantic Right Whales during Offshore Wind Farm Installation
}

Fiscal Year 2012 Progress Report

Offshore Wind Technology Assessment
TJ Carlson
AE Copping
MB Halvorsen
J Stavole
S Matzner

September 2012

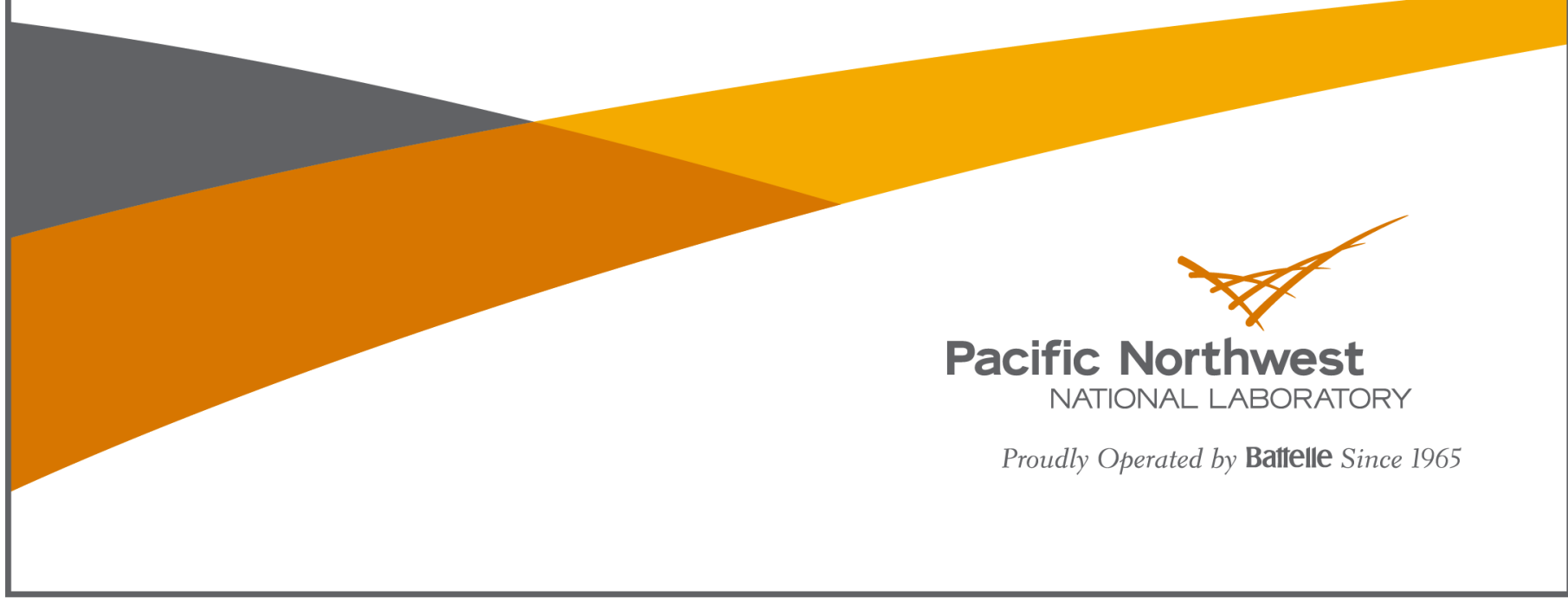





\title{
DISCLAIMER
}

This report was prepared as an account of work sponsored by an agency of the United States Government. Neither the United States Government nor any agency thereof, nor Battelle Memorial Institute, nor any of their employees, makes any warranty, express or implied, or assumes any legal liability or responsibility for the accuracy, completeness, or usefulness of any information, apparatus, product, or process disclosed, or represents that its use would not infringe privately owned rights. Reference herein to any specific commercial product, process, or service by trade name, trademark, manufacturer, or otherwise does not necessarily constitute or imply its endorsement, recommendation, or favoring by the United States Government or any agency thereof, or Battelle Memorial Institute. The views and opinions of authors expressed herein do not necessarily state or reflect those of the United States Government or any agency thereof.

\author{
PACIFIC NORTHWEST NATIONAL LABORATORY \\ operated by \\ BATTELLE \\ for the \\ UNITED STATES DEPARTMENT OF ENERGY \\ under Contract DE-AC05-76RL01830
}

Printed in the United States of America

Available to DOE and DOE contractors from the

Office of Scientific and Technical Information,

P.O. Box 62, Oak Ridge, TN 37831-0062;

ph: (865) 576-8401

fax: $(865) 576-5728$

email: reports@adonis.osti.gov

Available to the public from the National Technical Information Service

5301 Shawnee Rd., Alexandria, VA 22312

ph: (800) 553-NTIS (6847)

email: orders $w$ ntis.gov $<$ http://www.ntis.gov/about/form.aspx $>$

Online ordering: http://www.ntis.gov

This document was printed on recycled paper.

(8/2010) 



\title{
Monitoring and Mitigation Alternatives for Protection of North Atlantic Right Whales during Offshore Wind Farm Installation
}

\section{Fiscal Year 2012 Progress Report}

Offshore Wind Technology Assessment

\author{
TJ Carlson \\ AE Copping \\ MB Halvorsen \\ J Stavole \\ S Matzner
}

September 2012

Prepared for U.S. Department of Energy

the U.S. Department of Energy

under Contract DE-AC05-76RL01830

Pacific Northwest National Laboratory

Sequim, Washington 98382 



\section{Summary}

To be included in finalized version of this report. 



\section{Acronyms and Abbreviations}

$\mathrm{dB}$

$\mathrm{dB}$ re $1 \mu \mathrm{Pa}$

IQR

JNCC

$\mathrm{kHz}$

$\mathrm{km}$

LFA

$\mu \mathrm{Pa}$

$\mathrm{m}$

MMO

NARW

NMFS

NOAA

OCS

OSW

PAM

SL

TTS decibel(s)

interquartile range

Joint Nature Conservation Committee

kilohertz

kilometer(s)

Low Frequency Active

micropascal(s)

meter(s)

marine mammal observer

North Atlantic right whale

National Marine Fisheries Service

National Oceanic and Atmospheric Administration

Outer Continental Shelf

offshore wind

passive acoustic monitoring

source level

temporary threshold shift 



\section{Contents}

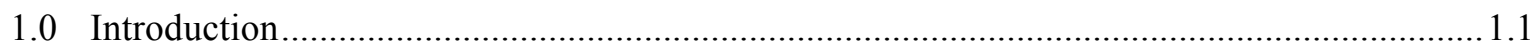

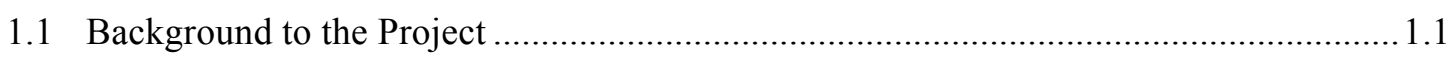

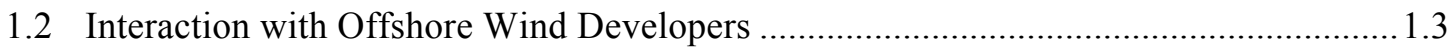

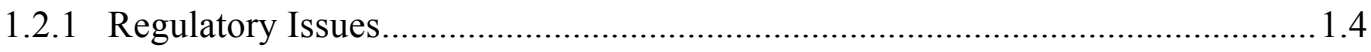

1.2.2 Measurement and Monitoring Uncertainty ..................................................... 1.4

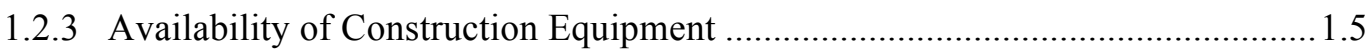

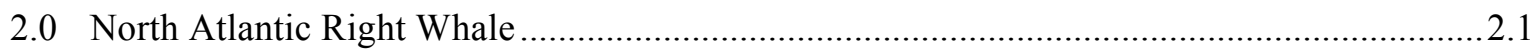

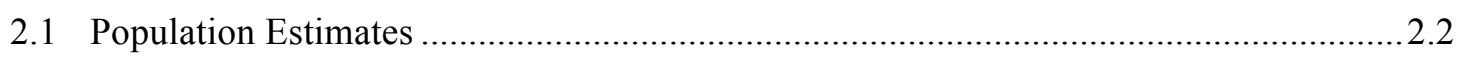

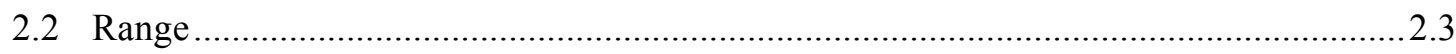

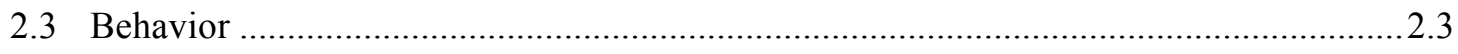

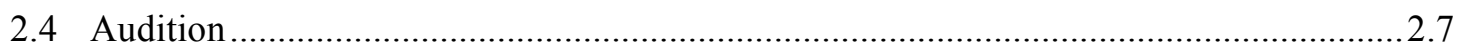

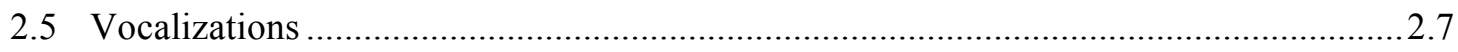

2.5.1 Behavioral Response of Mysticete Whales to Impulsive Sound .......................2.13

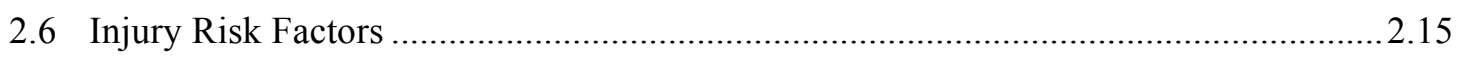

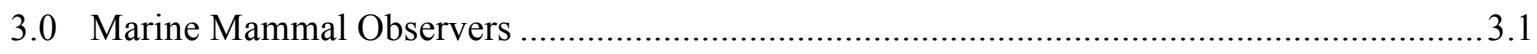

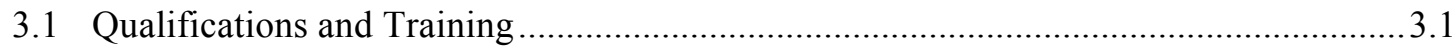

3.2 Protocols for MMO Monitoring (Metrics and Reporting) ........................................... 3.1

3.3 MMO Marine Mammal Detection Performance ......................................................... 3.2

3.4 Safety of Marine Mammal Observers at Sea .................................................................. 3.3

4.0 Passive Acoustic Monitoring .............................................................................................. 4.1

4.1 Fixed-Location PAM Detection, Classification, and Localization Performance ............. 4.2

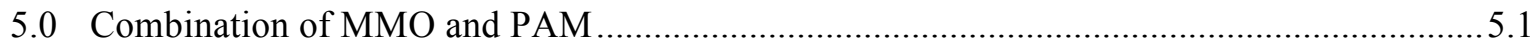

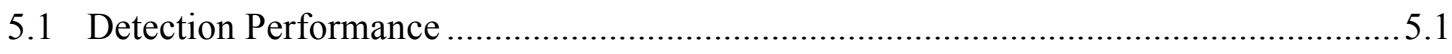

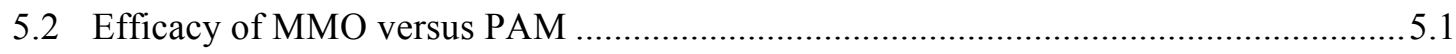

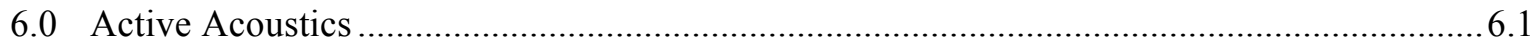

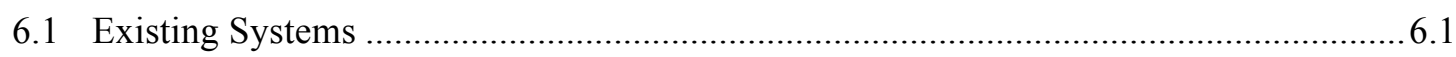

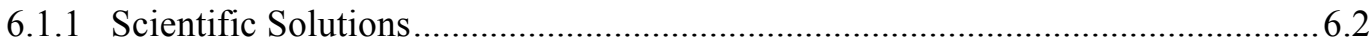

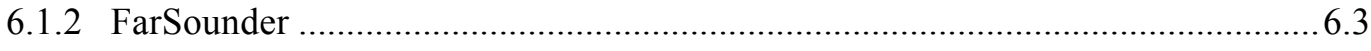

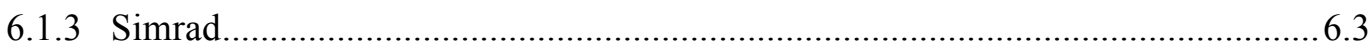

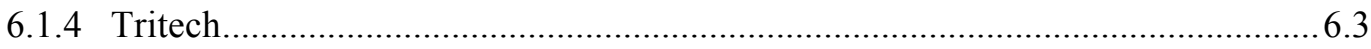

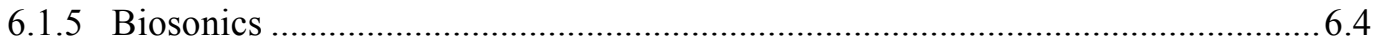

6.2 Expected Performance for NARW Detection during Pile Driving ..................................... 6.4

7.0 Initiation of Analysis for Exposure of NARW to Pile-Driving Sound ................................... 7.1

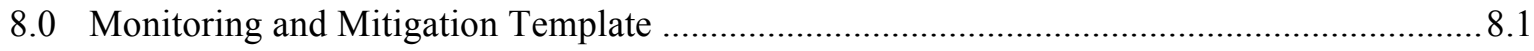

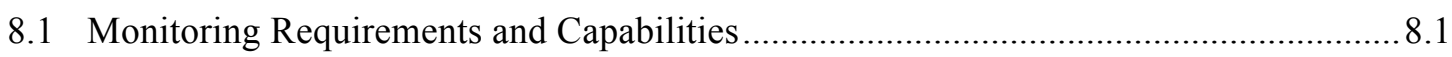

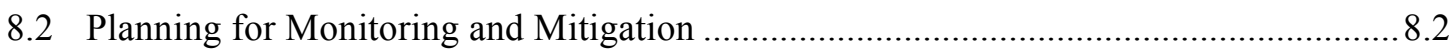




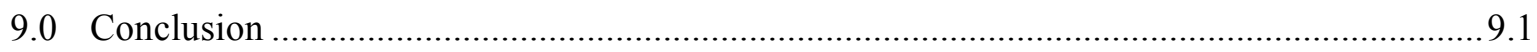

10.0 References 


\section{Figures}

1.1 Google Earth image showing the location of Mid-Atlantic offshore wind development sites.

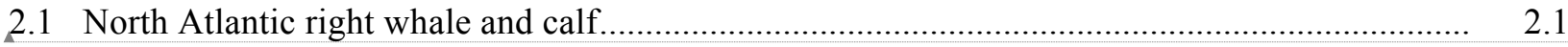

2.2 Range and migration path of right whale in western North Atlantic ...................................... 2.5

2.3 Monthly migration pattern and location........................................................................... 2.6

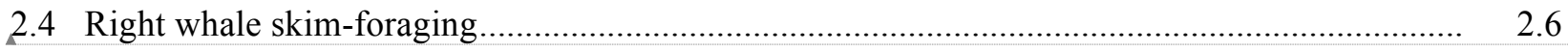

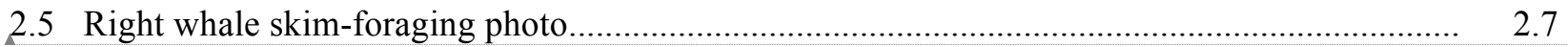

2.6 Spectrograms of the six call types: scream, warble, blow, up-call, down-call, and gunshot

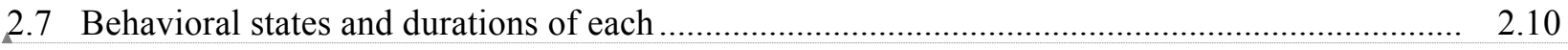

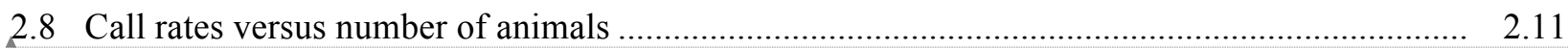

2.9 Calls over an 11-h time period by one female ................................................................... 2.12

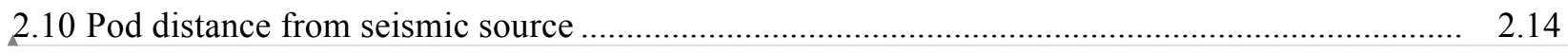

5.1 Number of individuals detected at three different stations ................................................. 5.1

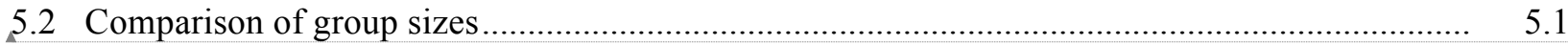

6.1 The predicted target strength of an animal using the model of Love (1971) although the model is not valid in this frequency range

6.2 The effective range of active sonar for detecting a NARW estimated using the sonar equation

\section{Tables}

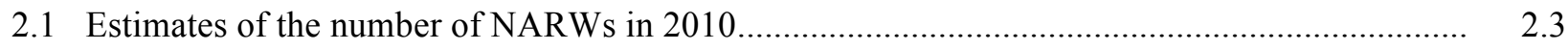

2.2 Call types recorded for surface active groups in the Bay of Fundy ........................................ 2.8

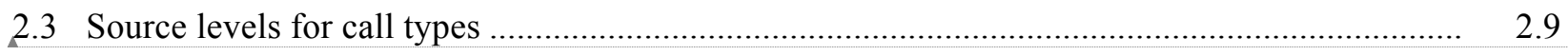

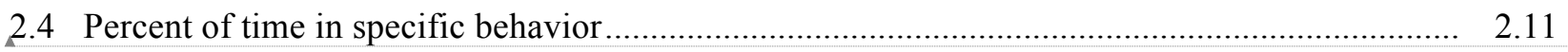

2.5 Meta-analysis of the above Figure 2.9 diving profile ...................................................... 2.12

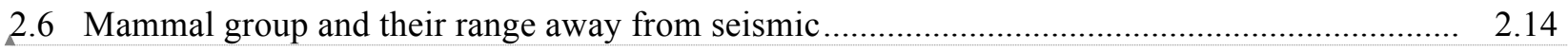

2.7 Direction of travel relative to seismic source.................................................................. 2.15

6.1 Summary of active acoustic marine mammal monitoring systems......................................... 6.2

7.1 The number of NARW sighted within radial distances from the center of proposed wind farm development sites off the Mid-Atlantic coast. 



\subsection{Introduction}

In late 2011, representatives of the U.S. offshore wind industry approached the U.S. Department of Energy Wind and Waterpower Program staff to express concern that regulatory requirements to protect North Atlantic right whales (NARWs) are likely to impose stringent limitations on the process of offshore wind installation off the Atlantic Coast. This project was designed to evaluate the potential risk to NARWs from the installation and operation of offshore wind farms, developing a cost-effective marine mammal monitoring system that will help provide the operational flexibility needed to meet challenging environmental conditions and unexpected construction complications. For the industrial activities associated with offshore wind development including pile driving, cost-effective marine mammal monitoring can assist with operational flexibility to meet the changing environmental conditions at sea and unexpected construction complications. This knowledge will be used to anticipate regulatory barriers and design-specific monitoring and mitigation strategies that will inform permitting discussions with regulators, leading to a shortened siting and permitting time frame.

\subsection{Background to the Project}

According to the U.S. Department of the Interior's Bureau of Ocean Energy Management (BOEM) Draft Environmental Assessment of Wind Energy Areas on the Mid-Atlantic Outer Continental Shelf (OCS), exposure to underwater sound and vessel collision have been identified as the highest risks to NARWs during site characterization, site assessment, and pile-driving operations that support the development of offshore wind on the Mid-Atlantic OCS (Knowlton and Kraus 2001; Bailey et al. 2010). The preferred operational alternative for mitigation measures to protect marine mammals and sea turtles, with focus on NARW, specifies the use of ship-based visual monitoring for the presence of marine mammals and sea turtles in critical zones around a moving vessel or near a construction activity. Sighting of animals at risk can be used to trigger a number of mitigation measures, most commonly the shutdown of activities or cessation of forward motion of ships, barges, or other support equipment until the animals have cleared the area (BOEMRE 2009). At this time, it is not clear what level of NARW siting would trigger a mitigation action; given the highly endangered status of NARW, potential harm or harassment to a single animal may be sufficient.

BOEM has recently proposed four potential sites for offshore wind development along the Atlantic Coast: Delaware, Maryland, New Jersey, and Virginia (U.S. Department of the Interior overview 2010, Figure 1.1). DOE stated that offshore wind resources along the American coasts are capable of producing $900,000 \mathrm{MW}$ of electricity, comparable to the current installed electrical capacity of the United States (EESI 2010). Although the United States has approved only one offshore wind project thus far, development has been occurring on a large scale worldwide since 1991; the first offshore wind farms were constructed in Denmark (EESI 2010).

Experience in protecting marine animals from the risks of underwater sound or collision with vessels is largely derived from oil and gas exploration and related construction activities. Each activity requires the use of qualified visual observers aboard survey vessels, while nighttime operations are generally not permitted for geophysical and sub-bottom surveys. Geophysical surveys commonly require a 500-m exclusion zone around the site; sub-bottom surveys require a 200-m exclusion zone. 
Pile driving also produces a substantial source of underwater sound that may place animals at risk. Mitigation measures for pile driving establish an exclusion zone $7 \mathrm{~km}$ in radius $\left(\approx 154 \mathrm{~km}^{2}\right)$, generally monitored by an observer near the sound source and a second observer on a moving vessel operating at a radial distance of 4 to $5 \mathrm{~km}$ from the sound source. Pile-driving operations are commonly required to cease when conditions do not permit visual monitoring or when animals enter the exclusion zone after commencement of the activity.

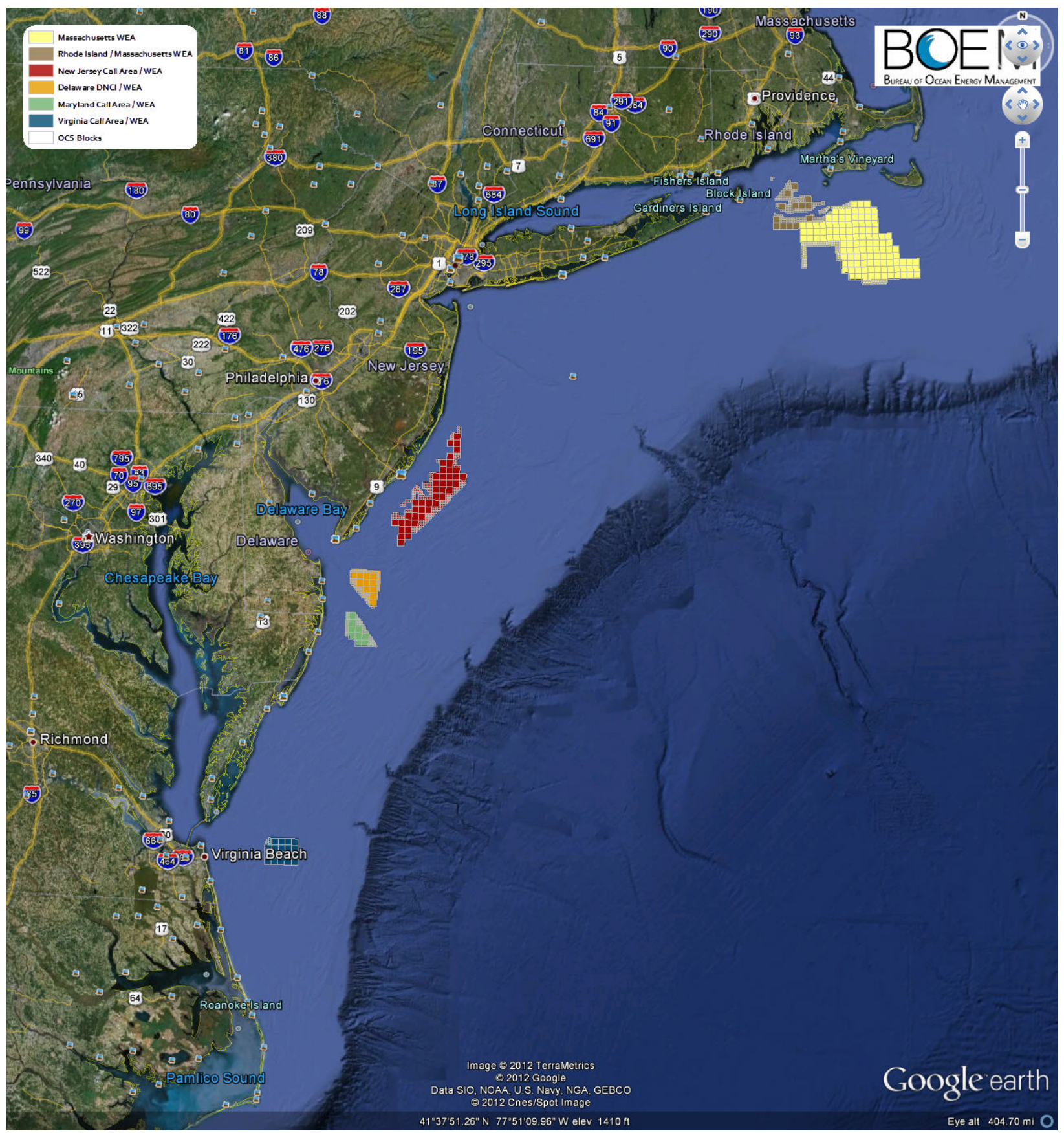

Figure 1.1. Google Earth image showing the location of Mid-Atlantic offshore wind development sites. 
This project seeks to manage the potential risk to NARWs from the development of offshore wind farms in the Atlantic and to develop a system of risk management that is portable to other offshore wind development areas where other potential impacts to other marine animals may be of concern. Steps to accomplish these goals will entail the ability to accurately detect the animals at sea, to locate and range NARWs in relationship to construction and staging areas associated with installation of wind turbines, and to integrate monitoring and mitigation activities into the installation and operational activities associated with offshore wind development.

Ensuring the safety of NARWs during offshore wind turbine installation will require real-time monitoring of the whales and mitigation measures when they are found in the vicinity of the installation operations, particularly those associated with pile driving. Installing wind turbines on the OCS will require that large-diameter steel shell piles be driven into the seabed, an operation that can extend for several days, depending on the number of foundations. Specialized equipment is needed, such as hammers, purpose-built vessels, and the trained crew to operate them. Mobilization, operation, and demobilization of this gear are very expensive; these expenses continue throughout the deployment period whether or not they are idled by inclement weather or other delays.

The purpose of monitoring actions around pile-driving operations is to detect the presence of marine mammals and inform necessary mitigation actions, which may require a number of actions including cessation of pile driving. The biology, life history, migratory movements, and susceptibility to noise must be considered in the development of effective monitoring and mitigation strategies. At present, the most commonly required monitoring for marine mammals around pile-driving operations is that carried out by ship-based marine mammal observers (MMOs).

In the remainder of this document, we will build the case for the feasibility of monitoring during pile driving that would include both MMOs and passive acoustic monitoring (PAM) and the role that active acoustic monitoring can play. We examine the biology, life history and noise susceptibility of NARWs, and investigate combinations of MMO and PAM monitoring, extensions of current monitoring technology, and the design of mitigation plans that are well integrated into the construction activity. The outcome of these efforts will be to allow the extension of pile-driving operations into the night and during daytime periods when visual monitoring for NARWs is not effective. By extension, many of the monitoring and mitigation strategies discussed will be transferable to offshore wind installation operations in other regions, in conjunction with other marine mammal species. Success in monitoring and mitigating for potential acoustic effects of pile driving and other development activities on marine mammals will depend on the geographic locations of proposed offshore wind development, the life history of the species of concern, and the ability to assure the regulatory community that these measures can protect the species.

\subsection{Interaction with Offshore Wind Developers}

Offshore wind developers and their consultants were asked to provide input on the need to examine the effects that regulatory protections for NARW might have on development in the Atlantic. Through direct interaction at the 2012 American Wind Energy Association conference, telephone conversations, and email exchanges, the offshore wind industry was asked to respond to the following questions:

1. Are you concerned that agency (National Oceanic and Atmospheric Administration [NOAA], BOEM) regulations could significantly affect offshore wind (OSW) development in the Atlantic? 
2. Are you most concerned about lengthy windows when you cannot pile drive (months of the year, nighttime), or the uncertainty of "flexible" rules that could change on you at any time as the agencies see fit?

3. What constraints do you have to when/how you can pile drive (availability of rigs, weather windows, timing including speed of mobilization)?

4. Would you consider the use of PAM in addition to or instead of MMOs if the addition of PAM would permit working through the night or during seasonal periods when construction activity is currently restricted?

5. Are there mitigation measures you would consider if they would allow longer piling periods?

6. Do your thoughts change on piling windows and mitigation measures if you are installing jacketed turbines versus monopoles?

\subsubsection{Regulatory Issues}

Feedback provided by the developers and their consultants indicated that they are concerned about the uncertainty surrounding regulations protecting NARWs at present, as well as expressing concern about how those rules might change in future. Respondents indicated they want to be included, along with other stakeholders, in the rule-development process. They stated the desire to have a voice in helping shape our country's renewable energy portfolio in a way that is timely and cost effective while protecting the living marine resources.

Some industry respondents are worried that NARW-related speed restriction zones currently in place seasonally along the U.S. Atlantic Coast could be extended to offshore construction. If those restrictions are put in place, it may further increase the cost of offshore wind installation and would ultimately increase the cost of energy. Such cost increases could occur because of limits to the time available to install offshore wind turbines, affecting the rate at which OSW can be deployed.

Generally, the offshore wind developers are concerned about the possibility of lengthy windows when pile driving is prohibited, but they are concerned also about the availability of weather windows needed to complete construction and how these two issues relate to one another. For example, in some geographic areas, NARW-related speed restriction zones correspond to preferred construction weather windows when the whales are not typically present. In such cases, OSW developers may not be as concerned as developers with projects located in areas where the weather window, NARW-related speed restrictions, and presence of the whales overlap.

\subsubsection{Measurement and Monitoring Uncertainty}

In addition, some OSW respondents indicated they are concerned about the uncertainty around the noise levels that will be allowed in the water column from OSW installation, including pile driving. Some respondents indicated that most sound mitigation measures are cost prohibitive and "... should be avoided whenever possible...." Some respondents indicated that they believe that any restrictions should be established in accordance with the level of sound energy associated with the specific application that is being deployed (e.g., jacket foundations, monopoles). They also specified that developers and contractors would have more certainty if sound-level thresholds were published and commonly available. 
Respondents indicated feeling that industry would consider the use of PAM, however, they mentioned that they understand its limitations and would not want to rely totally on PAM. Respondents indicated that the use of PAM and MMOs should be standardized so that the costs of environmental compliance may be understood and accounted for early in the feasibility process. As a whole, industry recognizes PAM as a relatively inexpensive technology relative to the costs of OSW construction if the technology will support longer construction windows.

Industry respondents stated that they are open to effective, commercially available, cost-effective mitigation measures that would allow for longer pile-driving periods.

\subsubsection{Availability of Construction Equipment}

OSW industry respondents agreed that availability of rigs, weather windows, and timing (including speed of mobilization) are real constraints to pile driving. Due the Jones Act which limits foreign-flagged vessels from transporting, constructing, installing, or maintaining any offshore wind devices coming from U.S. ports, one respondent expressed concern about the limited availability of Jones Act-compliant vessels capable of driving piles offshore in the United States. Other key factors that increase the complexity of OSW development are regulatory/environmental constraints and other governmental funding constraints (e.g., U.S. DOE FOA 000410) that stipulate OSW turbines must be in place and operational by a particular date in order to receive government funding. 



\subsection{North Atlantic Right Whale}

The NARW is in the suborder Mysticeti (Figure 2.1). The western stock is listed as endangered under the Endangered Species Act of 1973 and is also considered a critically endangered large whale population across the world (Clapham et al. 1999). About 10 years ago, North Atlantic and North Pacific right whales were classified as a single species and called "northern right whale." It has been genetically proven that these two populations represent separate species: the NARW (Eubalaena glacialis) and the North Pacific right whale (Eubalaena japonica) (Rosenbaum et al. 2000).

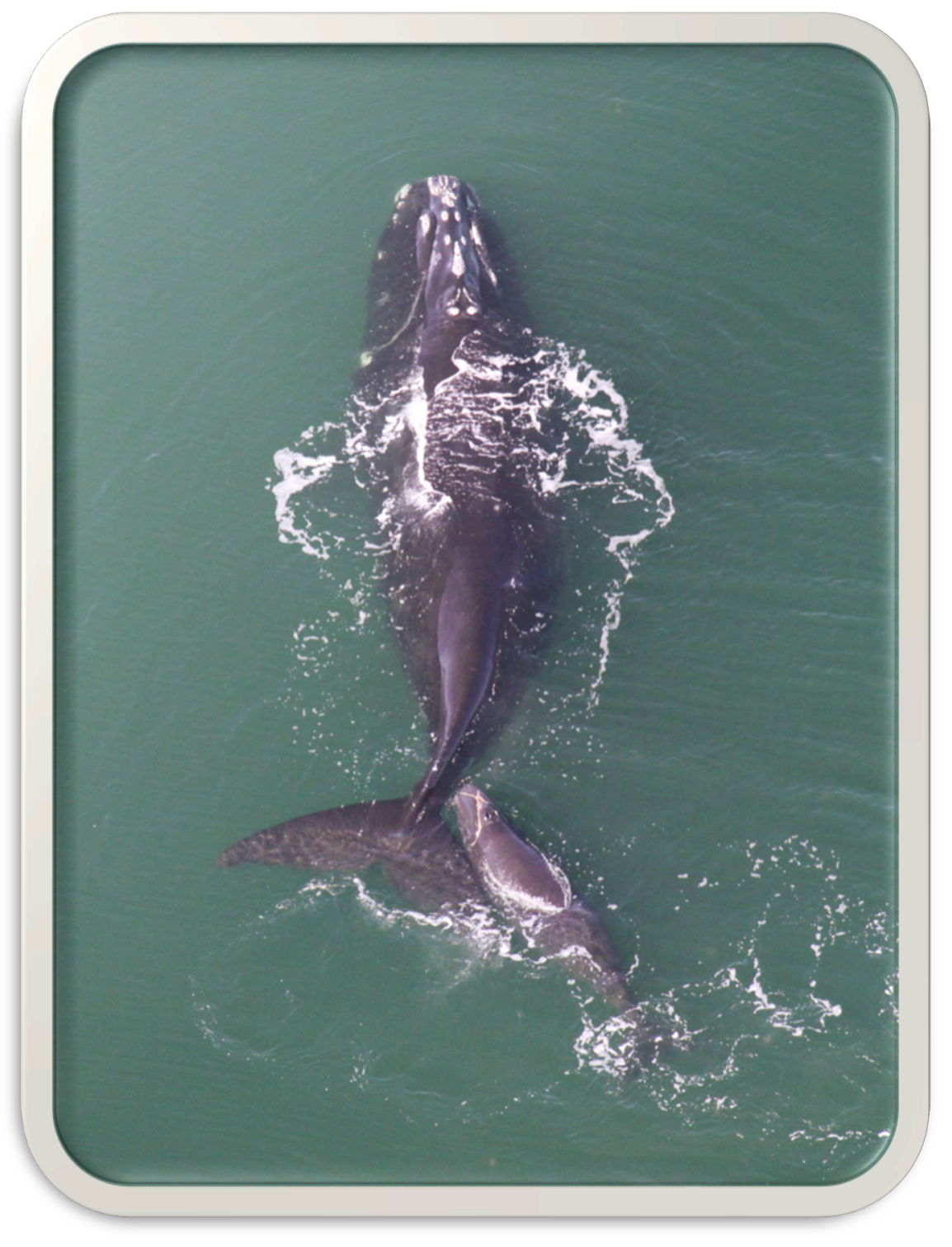

Figure 2.1. North Atlantic right whale and calf.

Eubalaena glacialis means "good/true whale of ice." Whalers considered them the "right whale" to hunt because they are found near shore, swim slowly, float when dead, and provide a large and profitable 
bounty of oils and baleen. Since the 1930s, NARWs have been protected worldwide by the First International Convention for the Regulation of Whaling. In the United States, shore-based whaling for NARW essentially stopped by 1900 , mostly because there were so few left, they were rarely encountered. Worldwide, these whales have been slow to recover, making them one of the most endangered whale species.

The right whale swims slowly, averaging $8 \mathrm{~km} / \mathrm{h}$, and can reach speeds of $16 \mathrm{~km} / \mathrm{h}$ in short spurts. However, these whales can dive down to $304 \mathrm{~m}$ and have been documented to remain submerged for up to 40 minutes; average descents are about 15 minutes. Before a dive, they usually make a series of five or six shallow dives and then submerge for about 15 minutes.

Right whales as a species can be identified by the absence of throat grooves, a lack of dorsal fin, and a V-shaped blowhole. They are individually identified by callosity patterns on the head region. Adults are about $15 \mathrm{~m}$ long; females are just a bit longer than males of the same age.

Right whales usually travel alone or in groups of 2 to 3 (up to about 12). If prey are dense, the whales may feed together, although usually they forage alone. The members that make up a group seem to be dynamic and changing, such that individuals have been observed moving between groups.

Mating takes place during the winter months and often involves aggregations of whales termed surface-active groups. These groups are usually centered around a single female and may involve large numbers of males. During any surface-active group, a lot of vocalizations are produced by the whales. Surface-active groups are observed in all seasons, although calving is highly synchronous and restricted to winter. Calving occurs primarily from December through March off Georgia and Florida coasts but has rarely been observed. Only $60 \%$ of known calves are seen with their mothers in summering areas (Rosenbaum et al. 2000), which implies that the location of mothers and calves is not fully known.

\subsection{Population Estimates}

The NARW population is considered to be highly endangered and is afforded federal protection under the Endangered Species Act of 1973. The animals are difficult to observe at sea and the size of the population is not well known; estimates are plagued by uncertainty and require trained observers to ensure that the best estimates are made. Monitoring the NARW population size depends on the observers' ability to recognize individual whales to ensure that the same whale is not counted repeatedly. The New England Aquarium curates the right whale identification database that contains more than 500,000 slides, prints, and digital images collected from 58,000 sightings of over 620 individual whales since 1935. For 2010 (the most recent year for which estimates are available), the best estimate is 490 individuals, based on the number of photographed whales. High and low estimates of the possible population size are also made, as shown in Table 2.1.

The greatest threats to the NARW population were historical whaling practices and, more recently, collisions with ships. Due to the combined efforts of conservationists, mariners, and NOAA, voluntary changes in shipping practices have reduced NARW collisions and deaths. 
Table 2.1. Estimates of the number of NARWs in 2010 (NARW Consortium 2011).

\begin{tabular}{|c|c|c|}
\hline Estimate & Number of Individuals & Estimation Techniques \\
\hline Low & 268 & 268 catalogued whales seen in 2010 \\
\hline Middle & 490 & 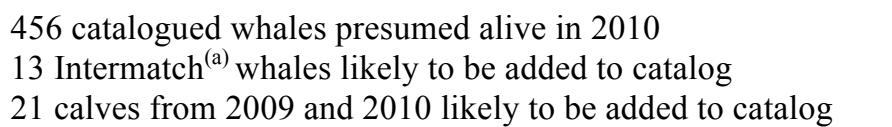 \\
\hline High & 680 & $\begin{array}{l}600 \text { All catalogued whales in } 2010 \text { minus those known dead } \\
24 \text { All active intermatch }{ }^{\text {(a) }} \text { codes without } 2009 \text { and } 2010 \text { calves } \\
56 \text { All uncatalogued } 2009 \text { and } 2010 \text { calves minus dead }\end{array}$ \\
\hline
\end{tabular}

(a) Intermatch codes are given to NARWs if two or more sightings match each other, and neither has been matched to a catalogued whale.

\subsection{Range}

The western NARW population range is between the calving grounds off the southeastern United States near Georgia and Florida up north to feeding grounds in Cape Cod and the Bay of Fundy, Scotian Shelf, and Gulf of St. Lawrence (Figure 2.2). Six critical habitats have been identified for these whales: the coastal waters of the southeastern United States; the Great South Channel; Georges Bank/ Gulf of Maine; Cape Cod and Massachusetts bays; the Bay of Fundy; and the Scotian Shelf. Movements within and between habitats are extensive. Although the number of NARWs remaining is highly uncertain, estimates range from 300 to upwards of 600 . During the winter months, the location of the population is mostly unknown (Waring et al. 2012).

The migration information was compiled for this report from several sources to build an illustrative graph of where the whales are and the duration of their stay, including Waring et al. (2012). The information in Figure 2.3 is not representative of the entire NARW population, nor is it comprehensive of all available literature. It provides a trend of the general migration pattern. There are few animals thus, few sightings to be certain of migration (Figure 2.3).

\subsection{Behavior}

NARW migrate for summer feeding to northern latitudes (near Georges Bank, in the Great South Channel, in the Gulf of Maine, in the Bay of Fundy, and over the Scotian Shelf (Cupka and Murphy 2005; Pace and Merrick 2008; Waring et al. 2012). In the fall and winter, they migrate south to temperate waters where breeding and calving take place. It has been suggested that it takes about 1 month for the migration between Florida and Cape Cod (Waring et al. 2012). In the process of designing monitoring and mitigation systems to detect and protect NARWs, the distribution of the animals is important: the habitat use and seasonal presence differs greatly from the Gulf of Maine and the southeast.

Right whales are known to be seasonal feeders, just like all baleen whales. Their diet consists of tiny crustaceans such as copepods, krill, and zooplankton. They feed by filtering prey from the water while swimming with their mouth open. Right whales feed near the surface (skimming) and also during dives. They are most vulnerable to ship strike when skimming at the water surface (see Figures 2.4 and 2.5). Baleen whales feed at all levels of the water column because the copepods undergo diel migrations, down during the day and ascend to near surface during the evening. In Cape Cod Bay, the water is shallow; 
during the day, the right whales do not need to dive for their food. However, in the Bay of Fundy, the water is deeper; during late summer, the copepods do not migrate to the surface, so the whales rarely skim feed in this region (Firestone et al. 2008). Zooplankton aggregations are a key feature of the feeding habitats populated by NARWs during the spring, summer, and fall (Werth 2012). 


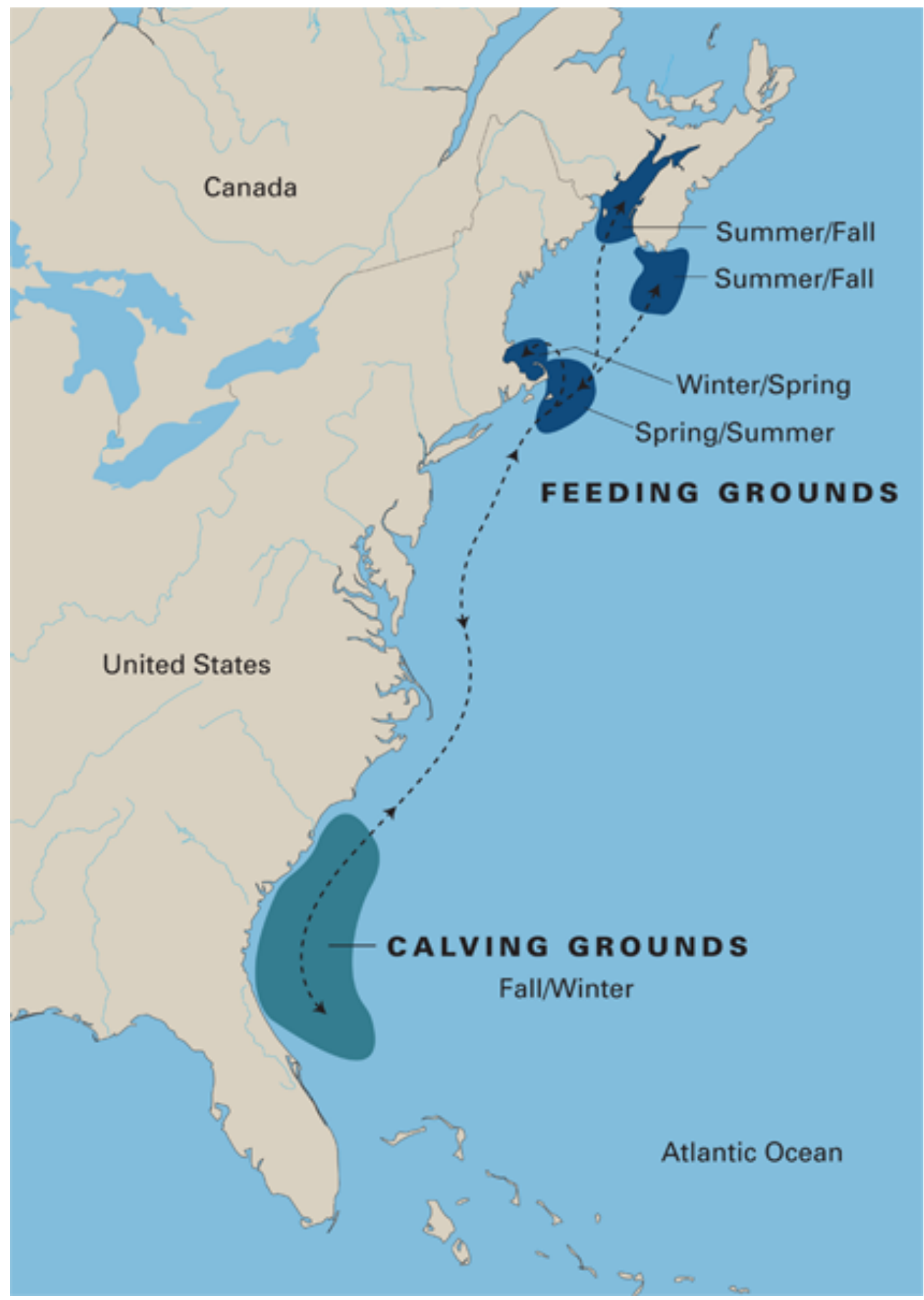

Figure 2.2. Range and migration path of right whale in western North Atlantic. (Illustration adapted from E. Paul Oberlander, Woods Hole Oceanographic Institution Graphics; Data from North Atlantic Right Whale Consortium; http://ocean.si.edu/ocean-photos/north-atlantic-rightwhale-territory.) 


\begin{tabular}{|c|c|c|c|c|c|c|c|c|c|c|c|c|}
\hline \multirow[b]{2}{*}{ LOCATION } & \multicolumn{2}{|c|}{ FALL } & \multicolumn{3}{|c|}{ WINTER } & \multicolumn{3}{|c|}{ SPRING } & \multicolumn{3}{|c|}{ SUMMER } & \multirow{2}{*}{$\begin{array}{l}\text { FALL } \\
\text { Sept }\end{array}$} \\
\hline & Oct & Nov & Dec & Jan & Feb & Mar & Apr & May & Jun & Jul & Aug & \\
\hline \multicolumn{13}{|l|}{ Florida/georgia/Carolinas } \\
\hline \multicolumn{13}{|l|}{ Females } \\
\hline \multicolumn{13}{|l|}{ others } \\
\hline \multicolumn{13}{|l|}{ Cape Cod } \\
\hline \multicolumn{13}{|l|}{ mother/calf pairs } \\
\hline \multicolumn{13}{|l|}{ others } \\
\hline \multicolumn{13}{|l|}{ Great South Channel } \\
\hline mother/calf pairs & & & & & & & & ?? ? & & & & \\
\hline \multicolumn{13}{|c|}{ others } \\
\hline \multicolumn{13}{|l|}{ Bay of Fundy } \\
\hline \multicolumn{13}{|l|}{ mother/calf pairs } \\
\hline \multicolumn{13}{|l|}{ others } \\
\hline \multicolumn{13}{|l|}{ Nova Scotian Shelf } \\
\hline mother/calf pairs & & & & & & & & & & ?? ? & & \\
\hline \multicolumn{13}{|l|}{ Mature whales } \\
\hline \multicolumn{13}{|l|}{ Migration Corridor } \\
\hline \multicolumn{13}{|l|}{ Pregnant females } \\
\hline others & & & & & & & & & & & & \\
\hline & Oct & Nov & Dec & Jan & Feb & Mar & Apr & May & Jun & Jul & Aug & Sept \\
\hline & & & & VINT & & & PRIN & & & JMM & & FALL \\
\hline
\end{tabular}

Figure 2.3. Monthly migration pattern and location.

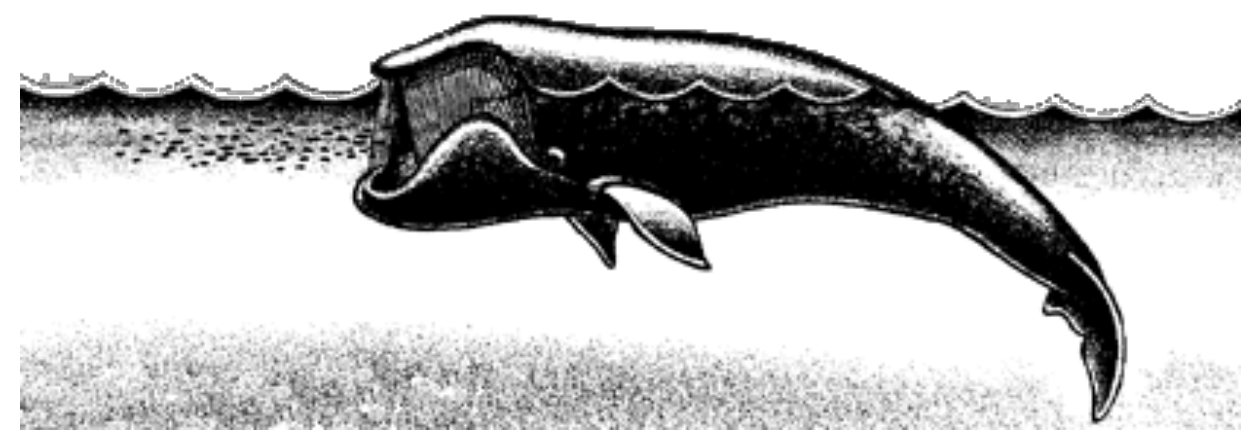

Figure 2.4. Right whale skim-foraging.

Baumgartner and Mate (2003) characterized feeding dives as a rapid descent from the surface to depths between 262 and $574 \mathrm{ft}$, remaining at depth for 5 to 14 minutes, then rapidly ascending to the surface. This behavior suggests that the whales are feeding on prey more abundant at the depths of the dives.

In an effort to prevent strike of NARWs by ships, the New England Aquarium makes daily flights during December through March over NARW calving grounds and informs ships traveling through the area of the locations of NARWs so the ships can avoid them. At this time, there is an iPod application that mariners can use to be informed of right whale sightings in the area. 


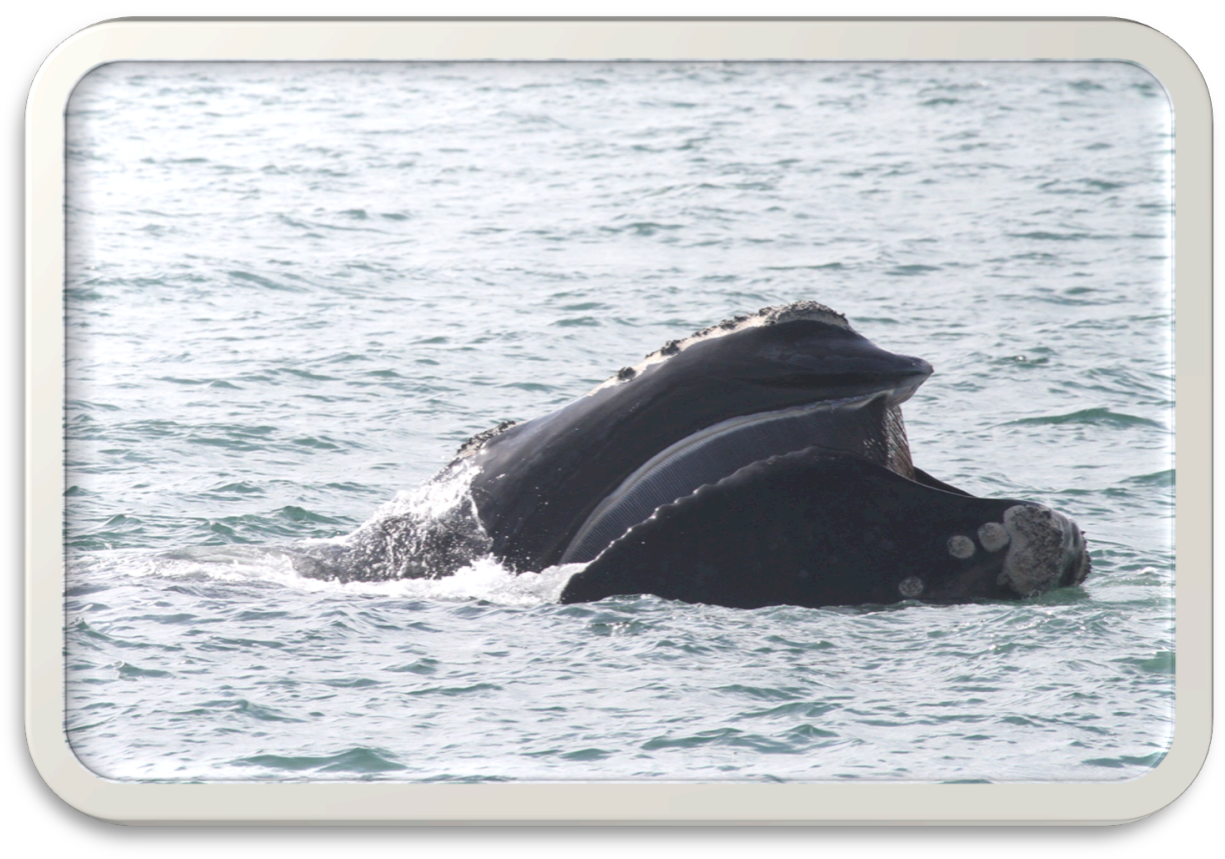

Figure 2.5. Right whale skim-foraging.

\subsection{Audition}

Until now, a hearing test (audiogram) on a live NARW has not been obtained. Therefore, analyses of inner ears using morphometric data acquired by necropsy of deceased individuals have been used to predict an estimated hearing range from approximately $10 \mathrm{~Hz}$ to $22 \mathrm{kHz}$ (Kenney et al. 1986, 1995). Based on analysis of vocalizations, the estimated frequency band of maximum hearing sensitivity is 100 $400 \mathrm{~Hz}$ (Parks et al. 2007).

Research by Nowacek et al. (2004) suggests that sound exposure levels of 133 to $148 \mathrm{~dB}$ re $1 \mu \mathrm{Pa}$ may disrupt feeding behavior. However, it is expected that the animals would resume normal feeding behavior within minutes of source cessation (Erbe 2002).

\subsection{Vocalizations}

NARWs generate a variety of sounds. The frequency bands for all of the various vocalization types are between $50 \mathrm{~Hz}$ and $15 \mathrm{kHz}$ (Commander of the U.S. Pacific Fleet and Third Fleet 2007), and calls with frequencies below $200 \mathrm{~Hz}$ and above $900 \mathrm{~Hz}$ are rare (Parks and Tyack 2005). Six major call types have been identified (Vanderlaan et al. 2003), as detailed in Table 2.2:

- scream (common in surface-active groups)

- gunshot (produced by males only);

- blow;

- up-call;

- warble; and

- down-call. 
The sound most often recorded is the "up-call," which sounds like a whoop. The up-call is likely a contact call to let surrounding whales know the caller's location. The up-call has been suggested as the best call to use for determining right whale presence (Mellinger et al. 2007; Parks and Tyack 2005). The frequency range of the up-call is $80 \mathrm{~Hz}$ to $3 \mathrm{kHz}$, with an average duration of 100 seconds and a source level SPLrms (Sound Pressure Level measured by the average amplitude of a sound wave or Root Mean Squared) of $150 \mathrm{~dB}$ re $1 \mu \mathrm{Pa}$ (SPLp-p of $166 \mathrm{~dB}$, or the sound pressure level measured by the range of the maximum positive sound wave peak to the maximum negative peak) (Figure 2.6 and Table 2.3). Up-calls most commonly recorded were produced at depths that ranged from 0 to $109 \mathrm{~m}(\mathrm{n}=264$, median $=2 \mathrm{~m})$, with an interquartile range (IQR) of 0.5 to $8 \mathrm{~m}$ (the range of the middle $50 \%$ of a data set). Tonal calls were produced at depths that ranged from 0 to $200 \mathrm{~m}$ (n $=107$, median $=4.6 \mathrm{~m}, \mathrm{IQR}=2.6$ to $40.5 \mathrm{~m}$ ), and gunshot calls at depth over the range from 0 to 11 $\mathrm{m}(\mathrm{n}=189$, median $=0 \mathrm{~m}, \mathrm{IQR}=0$ to $0.5 \mathrm{~m})$. The source levels for scream calls have been estimated at 172 to $187 \mathrm{~dB}$ re $1 \mu \mathrm{Pa}$ at $1 \mathrm{~m}$ (Clark and Clapham 2004; Mellinger et al. 2007; Parks et al. 2011). Adults produce longer up-calls than juveniles; otherwise, there seemed to be no vocalization differences. Both sexes and age classes produced up-calls. In addition, NARW have been reported to remain silent for hours (Gillespie and Leaper 2001).

Table 2.2. Call types recorded for surface active groups in the Bay of Fundy. The number of each call type and the duration, minimum, peak, and maximum frequency are listed in the table. For each measurement, mean \pm SD and range of values are presented. The related Southern right whale call types, as defined by Clark $(1982,1983)$, are also listed. Table from Richardson et al. (1995b).

\begin{tabular}{|c|c|c|c|c|c|c|}
\hline Sound Class & $\mathrm{n}$ & Duration (s) & $\begin{array}{c}\text { Minimum Frequency } \\
(\mathrm{kHz})\end{array}$ & $\begin{array}{l}\text { Peak Frequency } \\
\qquad(\mathrm{kHz})\end{array}$ & $\begin{array}{c}\text { Maximum Frequency } \\
\qquad(\mathrm{kHz})\end{array}$ & $\begin{array}{l}\text { Southern Right } \\
\text { Whale Types }\end{array}$ \\
\hline \multirow[t]{2}{*}{ Scream } & 2217 & Mean: $1.02 \pm 0.46$ & Mean: $0.42 \pm 0.21$ & Mean: $0.93 \pm 0.60$ & Mean: $6.03 \pm 2.94$ & High, hybrid, and \\
\hline & & Range: $0.22 \pm 4.55$ & Range: $0.15 \pm 1.05$ & Range: $0.13 \pm 4.10$ & Range: $2.28 \pm 18.95$ & pulsive calls \\
\hline \multirow[t]{2}{*}{ Gunshot } & 545 & Mean: $0.07 \pm 0.04$ & Mean: $0.15 \pm 0.17$ & Mean: $1.19 \pm 1.05$ & Mean: $15.59 \pm 6.63$ & Underwater slaps \\
\hline & & Range: $0.01 \pm 0.17$ & Range: $0.02 \pm 0.51$ & Range: $0.02 \pm 11.51$ & Range: $2.99 \pm 21.92$ & \\
\hline \multirow[t]{2}{*}{ Blow } & 315 & Mean: $0.76 \pm 0.25$ & Mean: $0.24 \pm 0.17$ & Mean: $1.64 \pm 0.89$ & Mean: $8.58 \pm 3.48$ & Blows \\
\hline & & Range: $0.33 \pm 1.82$ & Range: $0.02 \pm 1.07$ & Range: $0.16 \pm 6.13$ & Range: $0.91 \pm 20.37$ & \\
\hline \multirow[t]{2}{*}{ Up-call } & 211 & Mean: $0.99 \pm 0.35$ & Mean: $0.08 \pm 0.04$ & Mean: $0.19 \pm 0.05$ & Mean: $3.14 \pm 2.96$ & Up call \\
\hline & & Range: $0.45 \pm 2.08$ & Range: $0.05 \pm 0.16$ & Range: $0.11 \pm 0.51$ & Range: $0.25 \pm 11.23$ & \\
\hline \multirow[t]{2}{*}{ Warble } & 61 & Mean: $1.47 \pm 0.78$ & Mean: $0.47 \pm 0.25$ & Mean: $1.44 \pm 0.48$ & Mean: $8.41 \pm 4.20$ & Hybrid calls \\
\hline & & Range: $0.43 \pm 4.77$ & Range: $0.21 \pm 1.11$ & Range: $0.34 \pm 2.24$ & Range: $2.91 \pm 19.77$ & \\
\hline \multirow[t]{2}{*}{ Down-call } & 40 & Mean: $0.73 \pm 0.28$ & Mean: $0.28 \pm 0.11$ & Mean: $0.39 \pm 0.12$ & Mean: $1.54 \pm 2.15$ & Down calls \\
\hline & & Range: $0.26 \pm 1.80$ & Range: $0.02 \pm 0.51$ & Range: $0.14 \pm 0.64$ & Range: $0.25 \pm 10.50$ & \\
\hline
\end{tabular}

In a study by Parks et al. (2011), D-tags (suction-cup-attached multi-sensor digital recording tags) were attached on individual NARWs for an average of $4.5 \mathrm{~h}$ during the daytime only. They reported the duration of behavioral states (Figure 2.7) and the rate of calling that took place during those behaviors (Figure 2.8). The rate of calls varied from 0 to 200 calls per hour, and $168 \mathrm{~h}$ of acoustic data were recorded. In addition to the tagged whales, vocalizations made by any whale in the study area were recorded. 

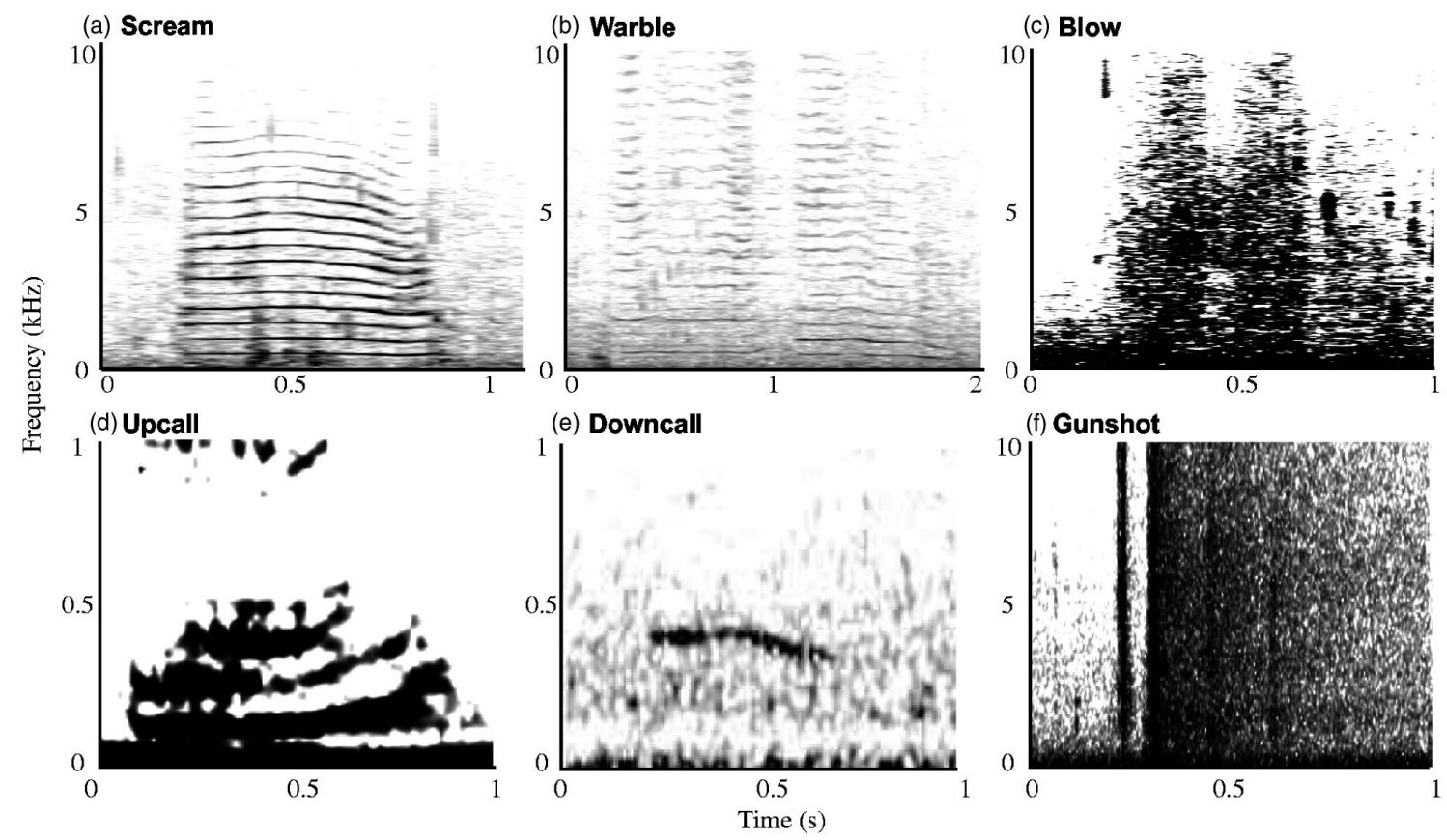

Figure 2.6. Spectrograms of the six call types: (a) scream, (b) warble, (c) blow, (d) up-call, (e) downcall, and (f) gunshot. The $x$-axes are time (s) and the $y$ axes are frequency (kHz). Note the different time and frequency scales for different call types. Analysis resolution $=28 \mathrm{~Hz}$ and $5.8 \mathrm{~ms}$ for (a)-(e). Analysis resolution $=112 \mathrm{~Hz}$ and $2.9 \mathrm{~ms}$ for (f). Figure from Parks and Tyack (2005).

Table 2.3. Source levels for call types. Calculated SL for five sound types all measured as $\mathrm{dB}$ re $1 \mu \mathrm{Pa}-\mathrm{m}$ from $50 \mathrm{~Hz}$ to $10 \mathrm{kHz}$. $\mathrm{N}=$ number of measurements; $\mathrm{SL}=$ calculated source level (p-p\rms). Table from Parks and Tyack (2005).

\begin{tabular}{lccccc}
\hline Broadband & $\begin{array}{c}\text { Screams } \\
(\mathrm{p}-\mathrm{p} \backslash \mathrm{rms})\end{array}$ & $\begin{array}{c}\text { Warbles } \\
(\mathrm{p}-\mathrm{p} \backslash \mathrm{rms})\end{array}$ & $\begin{array}{c}\text { Gunshot } \\
(\mathrm{p}-\mathrm{p} \backslash \mathrm{rms})\end{array}$ & $\begin{array}{c}\text { Up-calls } \\
(\mathrm{p}-\mathrm{p} \backslash \mathrm{rms})\end{array}$ & $\begin{array}{c}\text { Blows } \\
(\mathrm{p}-\mathrm{p} \backslash \mathrm{rms})\end{array}$ \\
\hline $\mathrm{N}$ & 31 & 3 & 12 & 3 & 10 \\
Minimum SL & $155 \backslash 137$ & $161 \backslash 144$ & $182 \backslash 155$ & $164 \backslash 147$ & $154 \backslash 137$ \\
Maximum SL & $175 \backslash 162$ & $165 \backslash 145$ & $201 \backslash 192$ & $168 \backslash 154$ & $166 \backslash 149$ \\
Mean & $164 \backslash 149$ & $163 \backslash 145$ & $191 \backslash 183$ & $166 \backslash 150$ & $162 \backslash 144$ \\
$\mathrm{SD}$ & $5 \backslash 8$ & $2 \backslash 1$ & $5 \backslash 5$ & $2 \backslash 4$ & $4 \backslash 4$ \\
\hline
\end{tabular}




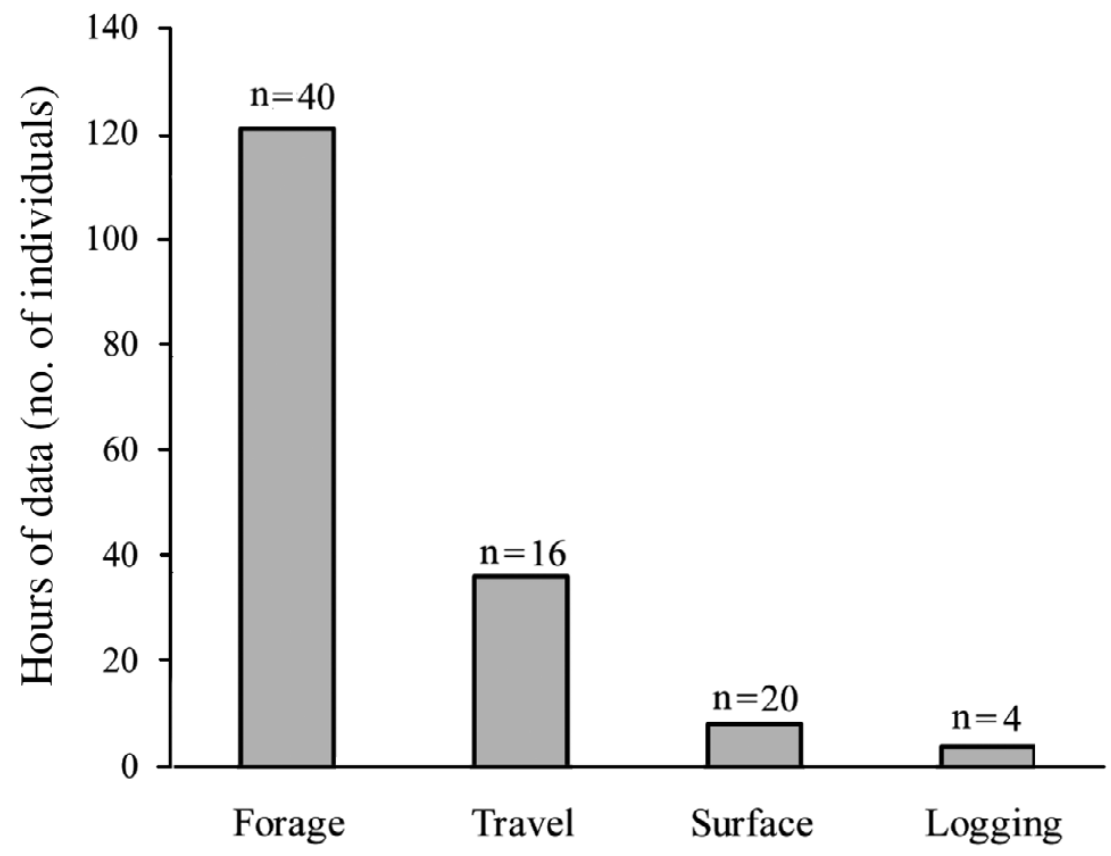

Figure 2.7. Behavioral states and durations of each. Number of tags (n) and total number of hours of data in each of the four behavioral states (foraging, traveling, surface activity, and logging). Figure from Parks and Tyack (2005).

The data from the Parks et al. (2011) study was analyzed in a different way here to help predict the probability of calling by daily activity type (Table 2.4). One caveat is that this data set represents only daylight hour vocalizations and behaviors. The estimated probabilities can be used to estimate the efficacy of mitigation plans that integrate PAM and MMOs. 


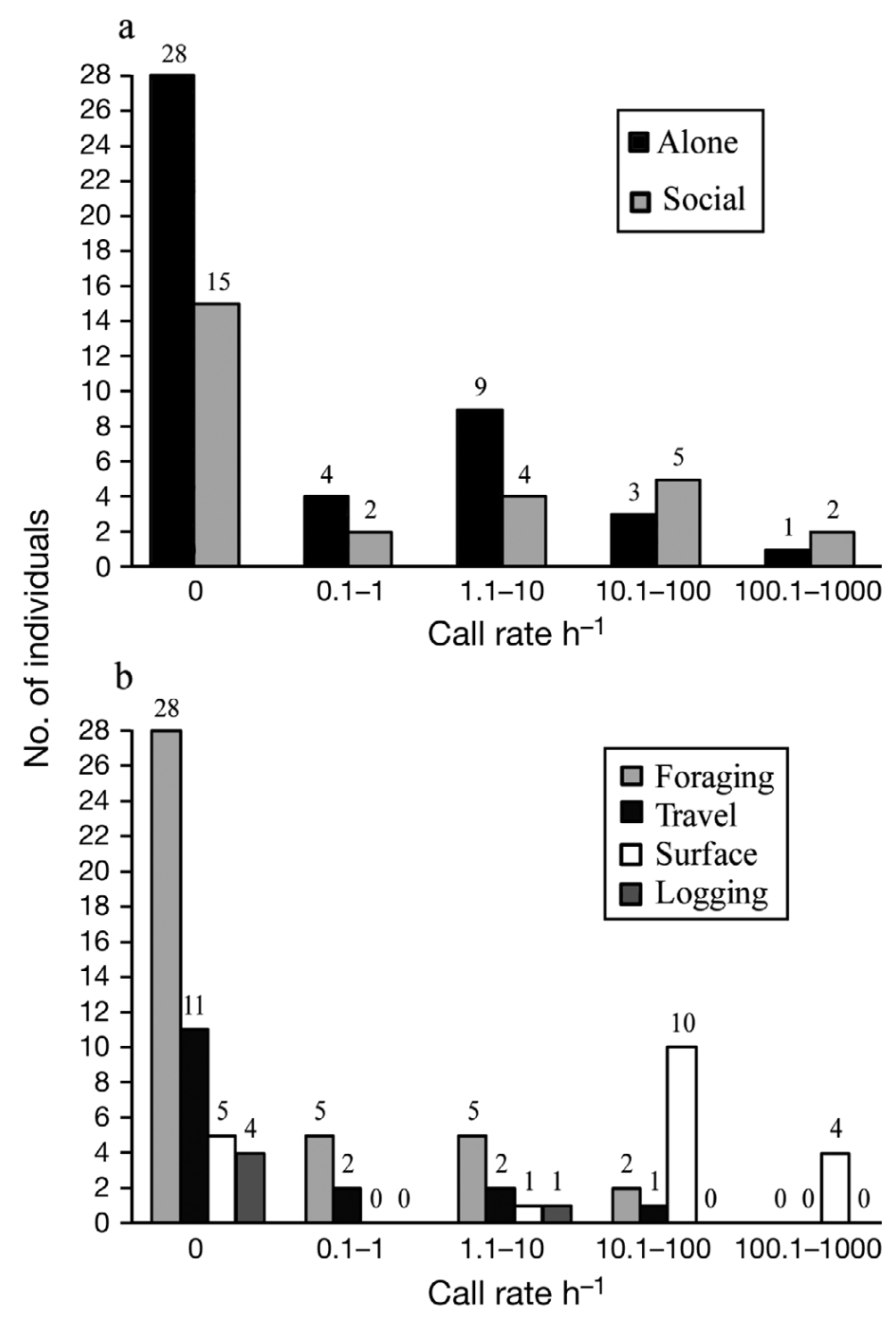

Figure 2.8. Call rates versus number of animals. (a) number of whales binned by call rates during social or alone time (signal-to-noise ratio $\geq 10 \mathrm{~dB}$ ); (b) call rate bins separated by behavioral states. Figures from Parks et al. (2011).

Table 2.4. Percentage of time in specific behavior. Derived from acoustic data hours form Parks et al. (2011).

\begin{tabular}{lcccc}
\hline & Foraging & Traveling & At Surface & Logging (rest) \\
\hline $\begin{array}{l}\text { Percentage of time } \\
\begin{array}{l}\text { Percentage of time } \\
\text { quiet }\end{array}\end{array}$ & 71 & 22 & 5 & 2 \\
$\begin{array}{l}\text { Percentage of time } \\
\text { calling }\end{array}$ & 30 & 69 & 25 & 80 \\
$\begin{array}{l}\text { Probability of call } \\
\text { During day }\end{array}$ & $32 \%$ & $\begin{array}{c}\text { During } \\
\text { night }\end{array}$ & $47 \%$ & 20 \\
\hline
\end{tabular}


An 11-h observation period of the diving and calling behavior of a single female is shown in Figure 2.9. The solid line shows the dive patterns of the animal, the gray circles when calls were made by this animal, and the circle around a star represents the calls made by conspecifics.

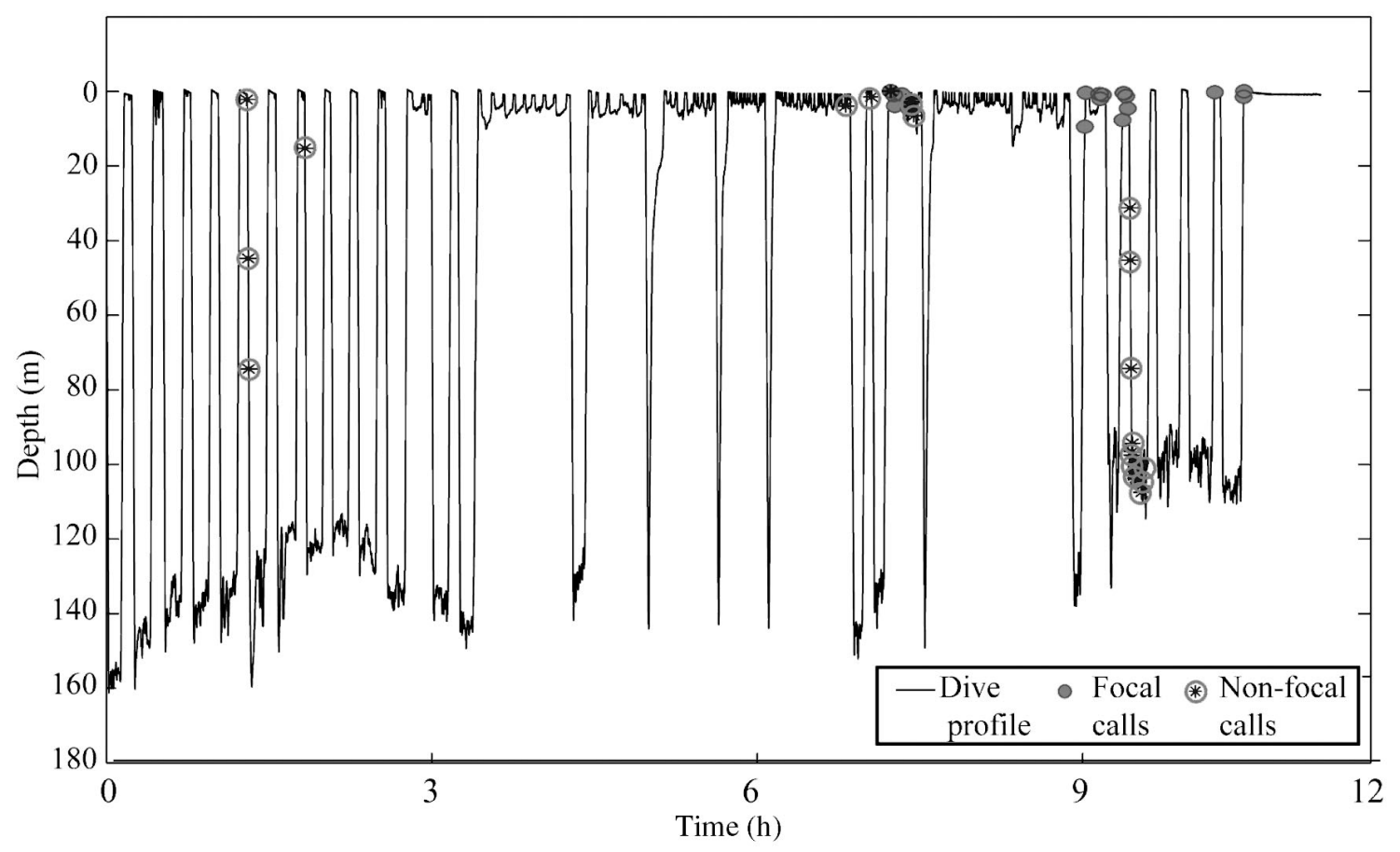

Figure 2.9. Calls over an 11-h time period by one female (figure from Parks et al. (2011).

The data presented in Figure 2.9, from the Parks et al. (2011) study, were also analyzed further here and used to predict the probability of calling during daylight activities (Table 2.5). It appears that conspecifics increase calls during diving/foraging behaviors, thereby increasing the chance of detecting the presence of non-vocalizing as well as vocalizing animals during foraging. Also, Parks et al. (2011) reported that the whales they tagged spent $36 \%$ of their time in the top $10 \mathrm{~m}$ of the water column, yet $77 \%$ (287 of 371) of tonal vocalizations (i.e., not gunshots) were produced at depths less than $10 \mathrm{~m}$.

Table 2.5. Meta-analysis of the above Figure 2.9 diving profile.

\begin{tabular}{ccc}
\hline Depth & Subject Calls & Conspecific Calls \\
\hline$<20 \mathrm{~m}$ & 16 & 6 \\
$>20 \mathrm{~m}$ & 0 & 12 \\
\hline
\end{tabular}

Passive acoustic detection of all call types should increase the probability of detecting the presence of NARWs because of the high calling rate of surface-active groups. Marine mammal observers working in conjunction with PAM systems greatly improves the opportunity to validate the accuracy of the PAM systems. Overall, observed call rates were low for most individuals, reflecting the greater allocation of time to behaviors like foraging (71\%) when call rates are relatively low. A study by Parks et al. (2011) reported that NARW vocalization rates were $44 \%$ higher during the night than during the day (Munger et 
al. 2008). The higher vocalization rates at night may be because of decreased foraging during the night. One of the caveats for using PAM is that most of the calling takes place in less than $10 \mathrm{~m}$ of water, which may complicate detection and localization of individuals (Matthews et al. 2001) because of complexities of shallow-water sound transmission. Although $90 \%$ of calls in the Munger et al. (2008) study were detected within tens of seconds to minutes of each other, others have reported that gaps in vocalizations can last from several hours to several days (Matthews et al. 2001). Matthews et al. (2001) reported a correlation between vocalization rates and group size, where lone whales produced $0-10 \mathrm{calls} / \mathrm{h}, 2-10$ whales produced $\sim 60$ calls $/ \mathrm{h}$, and more than 10 whales produced up to $700 \mathrm{calls} / \mathrm{h}$. These observations suggest that during mitigation when NARWs are more likely to aggregate, PAM should have a high probability of detecting the presence of NARWs.

A rough estimate of the probabilities of vocalization by NARWs during the day and night can be obtained using the data in Table 2.3 and the observation by Munger et al. (2001) of $44 \%$ higher vocalization rates at night compared to daytime rates. The product of the observed proportions of behaviors and probability of calling summed across behavior categories provides a rough unbounded estimate of the probability of an individual NARW calling during daylight hour of $32 \%$. When the higher likelihood of calling during night is considered, the probability of an individual NARW calling during the night was estimated to be on the order of $46 \%$.

\subsubsection{Behavioral Response of Mysticete Whales to Impulsive Sound}

We did not find any reports of observations of the behavioral response of NARW to pile-driving impulsive sound. However, the sounds generated by seismic airguns are similar to those generated by pile driving. Observations of the response of whales, particularly other mysticetes, may provide insight to possible responses of NARW to pile-driving sounds.

Mysticetes, as is the case for other cetaceans, appear to hear and exhibit behaviors that indicate some level of avoidance of intense impulse sounds. Observations of the behavior of whales show that they occurred farther from a large seismic airgun array during periods of shooting and tended to head away from the vessel when shooting was occurring, see Figure 2.10 (Munger et al. 2008; Parks et al. 2011). These results indicate that there may be at least some level of spatial avoidance of operating airguns, and possibly other impulsive sounds with similar characteristics, by mysticetes (Table 2.6). Avoidance of airguns has previously been observed in mysticetes in other regions (Stone and Tasker 2006). Overall, it appears that, as a group, mysticetes are more likely to occur at significantly greater distances from largevolume seismic sources when they are operating than when they are not (Richardsonet al. 1986, 1995a, 1999; Weller et al. 2002).

In addition to location relative to airgun arrays when the airguns were and were not operating, other changes in behavior have been observed. Changes in call detection rates in response to airgun activity have been found for bowhead whales, Balaena mysticetes (Stone and Tasker 2006). Other studies have also reported some level of stress, with alterations in surfacing, respiration, and dive cycles in mysticetes in response to airguns, sometimes at considerable distances from the source (Greeneet al. 1999). Furthermore, the direction of travel has been documented as moving away from seismic activities (Table 2.7). Although effects of active airguns on the physiology of the mysticetes are largely unknown, in one study, shorter blow intervals indicated an increase in the respiration rate of fin whales within $1 \mathrm{~km}$ of the airguns during periods of shooting (Ljungblad et al. 1988; Richardson et al. 1995b). 


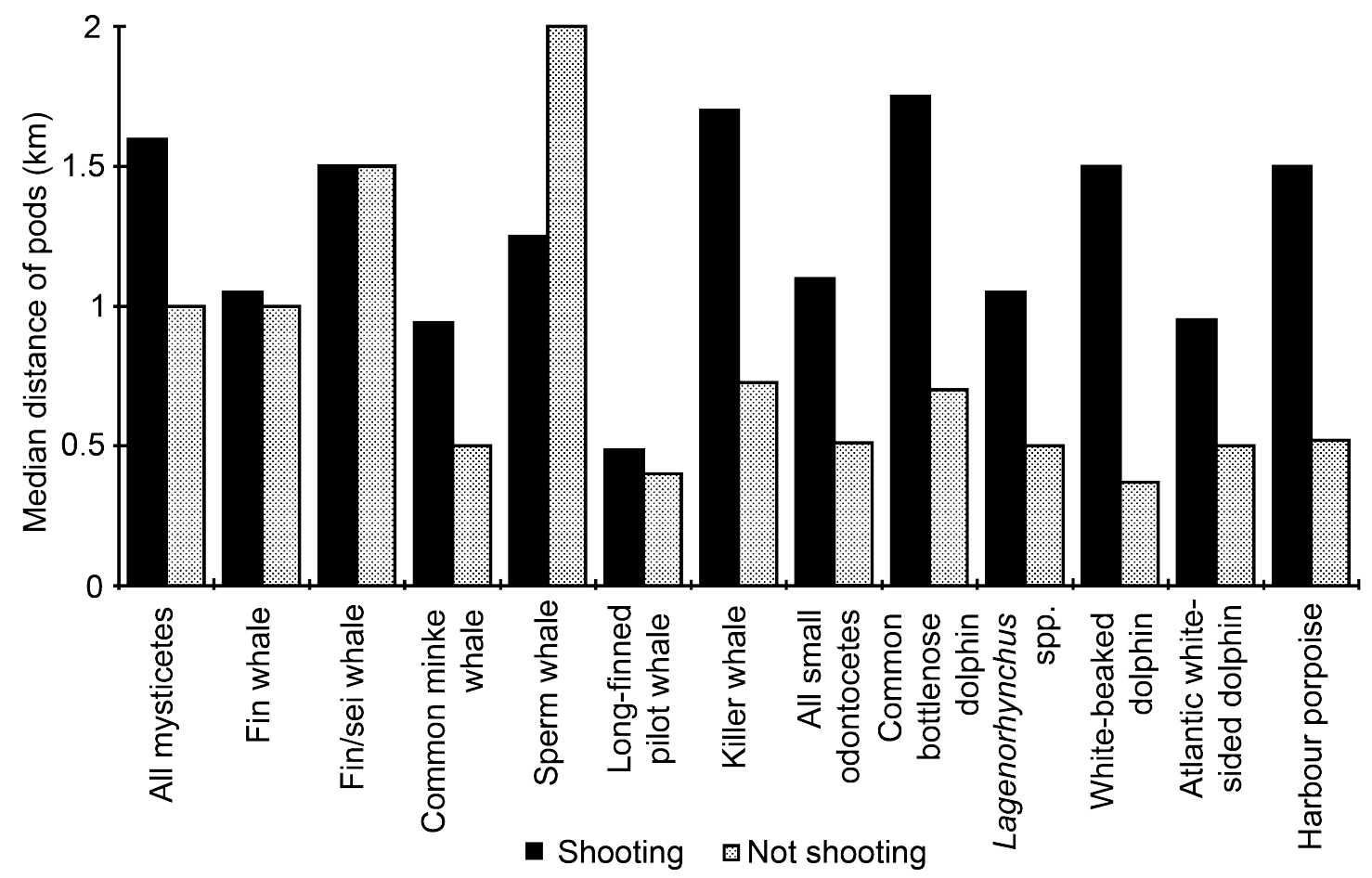

Figure 2.10. Pod distance from seismic source. Median closest distance of approach of cetaceans to large volume airgun arrays in relation to airgun activity (figure from Stone and Tasker 2006).

Table 2.6. Mammal group and their range away from seismic (table from Stone and Tasker 2006).

Difference in closest distance of approach of cetaceans to the airguns in relation to the use of large volume seismic airgun arrays (Wilcoxon test).

\begin{tabular}{lcrc}
\hline Species & $z$ & $n$ & $P$ \\
\hline All mysticetes combined & 2.529 & 148 & 0.0057 \\
Fin whale & 1.546 & 57 & n.s. \\
Fin/sei whale & 1.226 & 78 & n.s. \\
Common minke whale & 1.206 & 42 & n.s. \\
Sperm whale & -0.445 & 51 & n.s. \\
Long-finned pilot whale & -0.243 & 59 & n.s. \\
Killer whale & 1.843 & 14 & 0.0329 \\
All small odontocetes combined & 4.707 & 292 & $<0.0001$ \\
Common bottlenose dolphin & -1.701 & 14 & 0.0446 \\
Lagenorhynchus spp. & 4.464 & 164 & $<0.0001$ \\
White-beaked dolphin & 3.702 & 71 & 0.00011 \\
Atlantic white-sided dolphin & 2.428 & 80 & 0.0075 \\
Harbour porpoise & 2.503 & 21 & 0.0062 \\
\hline
\end{tabular}


Table 2.7. Direction of travel relative to seismic source (table from Stone 2000).

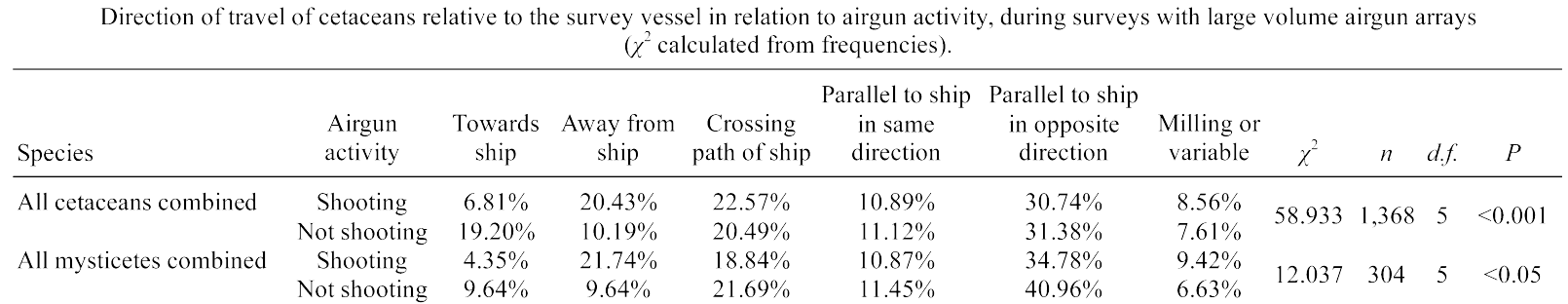

Although it is not possible, given available data, to state that NARWs will hear and exhibit avoidance behavior to pile-driving sounds or that they will exhibit other behavioral and physiological responses, the acoustic similarities between airgun and pile-driving impulsive sounds (Stone and Tasker 2006) and available data does indicate that such behaviors may be possible.

\subsection{Injury Risk Factors}

Because of their large size, right whales are prey only to orca, humans, and large sharks. Between 2005 and 2009, the average rate of human-caused mortality and serious injury to right whales was 2.4 per year (U.S. waters, 2.0; Canadian waters, 0.4). The causes of mortality and injury were entanglement in fishing gear and ship strike, with rates of 0.8 per year (U.S. waters, 0.8; Canadian waters, 0) and 1.6 per year (U.S. waters, 1.2; Canadian waters, 0.4), respectively. The rates of human-caused mortality and injury, while based on the best available information (Halvorsen et al. 2012), are believed to be minimum. 



\subsection{Marine Mammal Observers}

Marine mammal observers (MMOs) are individuals trained to visually detect and identify marine mammals species during monitoring activities conducted in compliance with the Marine Mammal Protection Act of 1972, and operating permits by regulatory authorities for activities such as seismic surveys and pile driving. For example, BOEM is responsible for applying mitigation measures that protect marine animals and turtles during seismic activity that takes place in the Gulf of Mexico. In this region, MMOs are called Protected Species Observers. Protected Species Observers and PAM operators are required to participate in training courses recognized by the BOEM (http://www.intelligentocean.com/AboutMMOs.htm).

\subsection{Qualifications and Training}

BOEM and the Joint Nature Conservation Committee (JNCC) have set a standard for the content of courses and training of MMO and PAM operators. The JNCC appears to have the authority to approve and certify other training centers to following the standards and protocols set forth by BOEM. The standards set by the JNCC are recognized and usually required worldwide. Operating permits often require that only trained and certified MMOs are permitted to perform MMO duties.

MMO responsibilities are to detect protected species, visually and/or acoustically (PAM) and, in the case of seismic surveys, notify the airgun array operator about the presence and location of the animals so that mitigation actions, if required, can be initiated. In the case of seismic surveys, at least two MMOs are required to be on board at all times during daylight (dawn to dusk) while seismic operations are being conducted. Atmospheric conditions such as fog, rain, and darkness can reduce visibility and make detection of marine mammals an impossible task. Evolving protocols for the use of PAM in conjunction with MMOs are permitting some flexibility for continued operation of seismic operations when conditions for visual detection of marine mammals are poor but still satisfactory for detection of vocalizing marine mammals by PAM.

When an animal is observed during seismic operations, mitigation actions may include changing the vessel's course, shutting down the airgun array, or other action that will reduce the risk of exposing marine mammals to high levels of impulsive sound. Even if marine mammals are not observed at startup of an airgun array, the amount of sound generated by the array will be managed so that it gradually increases (i.e., ramp-ups) for 20-40 minutes until operational levels are reached (Waring et al. 2012). The idea here is to give any marine mammals that may be in the vicinity of the airgun array an opportunity to leave before sound levels become high.

\subsection{Protocols for MMO Monitoring (Metrics and Reporting)}

Monitoring of marine mammals is used for many industrial activities that range from fishing to seismic explorations. When trained MMOs are aboard a vessel or observation perch, they are often required to collect a variety of information in addition to the obvious identification of the species of marine mammals observed. Other information collected includes, but may not be limited to, identification of individual animals, the distance between the animal and the activity (pile being driven or airgun array), the trajectory of the animal(s), the number of animals, number of calves, behavioral states 
and/or responses, weather conditions, sea state, and visual acuity, all of which are recorded into a data book (Barton et al. 2008; NTL-2012-Joint-G02 2012). MMO observation databases that contain data acquired following JNCC protocols have been evaluated to have the most thorough and comprehensive information (Barton et al. 2008).

Visual surveys of marine animals can provide detailed information about behavior, distribution, and abundance. The platforms from which MMOs work include aircraft, vessels, land, and various combinations of these. Depending on the species, vessel surveys are often preferred because of the near animal proximity that can be obtained and the control over vessel speed that permits longer time periods to observe detected animals, which enhances confidence in identification of species and estimation of other parameters. Aerial surveys are preferred for some species because of the inherent difficulty in observing these animals from vessels because of their physical or behavioral characteristics. Aerial observations permit better visualization of animals below the ocean surface down to $10 \mathrm{~m}$ in depth under some conditions as well as enhanced observation of specific behaviors (Patenaude et al. 2002; Richardson et al. 1986; Würsig et al. 1989). The combination of aerial- and ship-based visual and PAM has been used successfully for population census (e.g., Brower et al. 2011; Waring et al. 2012).

Environmental factors that put MMOs at a disadvantage for visual detection of animals are light level or darkness, sunshine blindness or glare, fog, and sea state such as large swells, and when animals are submerged for long periods. Other factors are the location of observers (i.e., vessel, shore, aerial), lack of training or experience, distraction by other tasking, lack of appropriate equipment and protocols, blocked or obstructed visibility lines, and fatigue from long work periods.

BOEM assembled a panel to develop recommendations for improvements to its MMO program. The panel addressed the challenges for MMOs, including times when visibility is reduced such as from weather, fog, sea state, or darkness. Suggestions for improving detection of species of vocalizing marine mammals during these times focused on the use of PAM implemented so that acquired signals were processed as received and detected species identified (classified) and localized relative to the standoff safety zones required for protection from high levels of sound. Immediate (real-time) processing of PAM under these conditions potentially provides an analogue, to an acceptable extent for vocalizing species, for visual observation by MMOs (Brower et al. 2011).

\subsection{MMO Marine Mammal Detection Performance}

Few studies have been conducted to evaluate the efficacy of MMOs for detection of marine mammals. The Joint industry Programme, (JIP) conducted a survey to identify MMO data sets and to evaluate if there was enough uniformity to compile separate data sets into comprehensive databases and perform detailed analysis of the data to answer questions of importance to oil and gas producers. The JIP found that one group, the JNCC, had data sufficiently uniform to be readily assembled into a comprehensive database while the vast majority of other data owners did not. Also, the JNCC reported that it had conducted detailed analysis of its data sets whereas other regulators had not (Barton et al. 2008).

There is a clear lack of analysis of existing databases. Although these data may contain information that could answer questions of importance about marine mammal populations, current practice for utilization of MMO data does not encourage such analysis. Funding for MMO activity is focused on the 
conduct of the industrial activity and any follow-on utilization of the bulk of data is separate from the activity under way when it was acquired.

A study was found that directly investigated MMO efficacy. This study, conducted in 2007, examined the effectiveness of MMOs in reducing risk of ferry collisions with marine mammals. MMOs on ferries were able to locate animals beyond $400 \mathrm{~m}$ more often than the ferry captain (who was quasitrained in detection/observation). This increase in distance provided more time for maneuvers to avoid collision (Weinrich and Pekarcik 2007). Overall, the average visual detection probability of marine mammals by trained MMOs was determined to be less than 50\%. Although there have been few studies to determine the efficacy of marine mammal detection by MMOs, a very large body of literature addresses this issue as an element of surveys to estimate the abundance of marine mammals. Most likely, the best approach to assessing the efficacy of MMO detection of marine mammals is to compare their operating protocols and other elements of their actions, including weather and other variables, with studies that consider the statistical properties of marine mammal surveys that use line transect or similar designs.

It appears that the effectiveness and performance of marine mammal monitoring programs would significantly benefit from the establishment and support of an international database that is standardized and readily available online (Barton et al. 2008; Brower et al. 2011). Such a database would be even more powerful if it were paired with PAM and other underwater sounds, both anthropogenic and biological. Since 1994, the National Research Council had identified the need for such a comprehensive database, and this gap in information and analysis continues (Southall et al. 2007; Southall and Novacek 2009).

\subsection{Safety of Marine Mammal Observers at Sea}

Ensuring the safety of personnel at sea during the development of offshore wind is the highest priority for operations that support site investigations, construction, and monitoring for potential environmental effects. MMOs are typically stationed on ships and barges in proximity to construction operations, although they may also be assigned to observe the presence of marine mammals from low flying airplanes. Either vantage point introduces inherent dangers to the collection of data that must be mitigated by rigorous training programs, safety plans and procedures, and a robust back up of personnel and procedures to respond to changes in protocols, inclement weather, or unforeseen circumstances. 



\subsection{Passive Acoustic Monitoring}

PAM as an element of monitoring to achieve compliance with operating permits for marine construction activities, is in its infancy. The basic science and engineering principles for PAM to detect, classify, and localize marine mammals are well understood and have been applied to achieve a wide range of civilian and military measurement objectives. At a workshop held in 2009 sponsored by BOEM, the current state of the art for PAM systems, both mobile and fixed location, was reviewed (SEIC 2007). Three conclusions of the workshop are particularly relevant to consideration of marine mammal monitoring methods that might permit operational flexibility for pile-driving operations. The first is that the effectiveness of marine mammal monitoring for offshore industries such as pile driving can be increased by using a combination of MMO and acoustic methods. The second is that although the overall specifications for the acoustic portion of a monitoring plan can be generalized, specific site requirements and the marine mammal species of interest require some level of customization of the acoustic monitoring system to be deployed. The third is that although fixed-location PAM technology is more mature than mobile PAM or active acoustic monitoring, there is not a one-size-fits-all solution for a fixed-location PAM system to monitor for the presence and location of vocalization marine mammals during pile driving.

The use of mobile (towed) PAM has been integrated into the marine mammal monitoring elements of seismic surveys. At present, mobile PAM is treated as a permitted optional technology. The attractiveness of mobile PAM to seismic survey operators is that it is understood well enough by regulators that, if present, may permit seismic operations to continue when visual conditions are poor for MMOs, such as during darkness and inclement weather, or may facilitate the startup of seismic operations (Bingham 2011). In contrast, PAM is not widely utilized to monitor for the presence of marine mammals in safety zones during pile driving.

As has been the case with towed PAM deployed for seismic surveys, deployment of fixed PAM to monitor for marine mammals during pile driving must provide economic or operational benefits to the pile-driving activity and enhance protection of marine mammals from exposure to high levels of impulsive sound. A potentially significant economic benefit to the pile-driving activity would be to permit operations during periods when MMOs cannot function, such as during the night and when the weather is poor. It has taken several years and a number of deployments for towed PAM to become accepted as a viable element for marine mammal monitoring during seismic surveys. It is possible that elements of the experience gained applying towed PAM to enhance marine mammal monitoring may expedite development of deployment and operational protocols for fixed PAM deployments. One area that warrants study is the means used to integrate towed PAM into the operation of seismic vessels. Critical factors identified for successful integration of towed PAM are communication between the seismic crew and the marine mammal monitoring crew and clear protocols to implement operational changes to the airgun array and/or the course of the seismic vessel when warranted by towed PAM detections of marine mammals. Also important will be understanding the factors that regulators considered to permit operation of seismic vessels when MMO monitoring is not possible. 


\subsection{Fixed-Location PAM Detection, Classification, and Localization Performance}

A great many possible configurations for a fixed PAM baseline array affect the detection, classification, and localization performance of the system. It is assumed that fixed PAM for marine mammal monitoring will need to perform detection, classification, and localization of vocalizing marine mammals as is the case for towed PAM. It is also assumed that, unlike research applications in which there is typically little urgency in the processing of data, industrial applications will require that all three tasks be performed in real time or near-real time to protect marine mammals, in order to contribute to management of pile-driving activities.

In order to reliably detect marine mammals such as NARWs, understanding the biology and ecology of the species is critical. The use of specific habitats, timing of migration, and likely group size of animals traveling together are necessary inputs to tune and validate detections by a PAM system, Detection of marine mammals using PAM depends on vocalization by the animal and on detection of the vocalization by the PAM system. An animal that is not vocalizing is invisible to a PAM system.

Mellinger and Barlow (2003), Barkaszi et al. (2012), and Mellinger et al. (2007) discuss the benefits and limitations of PAM. There are varieties of detection approaches and algorithms that can be implemented to function in real time. The performance of a detector is judged by its ability to detect a vocalization when one is present and to have a minimum rate of false detections. In practice, detectors are usually optimized for a specific call type. There are similar requirements and performance considerations for classification of detected vocalization to the probable source. Finally, the localization of a calling animal is a function of many factors, including the geometry of the receiving baseline array.

The next steps in consideration of PAM as an element of a marine mammal monitoring system for pile driving during wind farm construction are to determine 1) the technical requirements of a fixed PAM system; 2) in collaboration with pile-driving contractors, determine how the system might be integrated into normal pile-driving activities; and 3) with the help of wind farm developers, develop an understanding of the cost/benefit considerations for inclusion of PAM into wind farm construction. 


\subsection{Combination of MMO and PAM}

\subsection{Detection Performance}

Evidence is accumulating that using a combination of monitoring approaches can increase the effectiveness of marine mammal monitoring and mitigation. For example, mammal observers in combination with towed PAM has shown benefits for protection of marine mammals and increased seismic operation flexibility. Similarly, a combination of fixed PAM and active acoustics may provide an improved understanding of apparent changes in the distribution of calling whales responding to industry sounds, a problem that has plagued at least some studies that relied only on a fixed PAM system.

\subsection{Efficacy of MMO versus PAM}

Assessment of the relative marine mammal detection performance of MMO and PAM methods aids assessment of the benefits of combining the methods for marine mammal monitoring (Figures 5.1 and 5.2). A study done by Kimura et al. (2009) compared visual and acoustic monitoring of the Yangtze finless porpoise (Neophocaena phocaenoides asiaeorientalis). Acoustically the porpoise was detected approximately $82 \%$ of the observation times versus visual detection of about $13 \%$ of the observation times. The PAM underestimated group size due to limited resolution of bearing angles, yet was more accurate than visual, especially with low-density populations (Kimura et al. 2009).

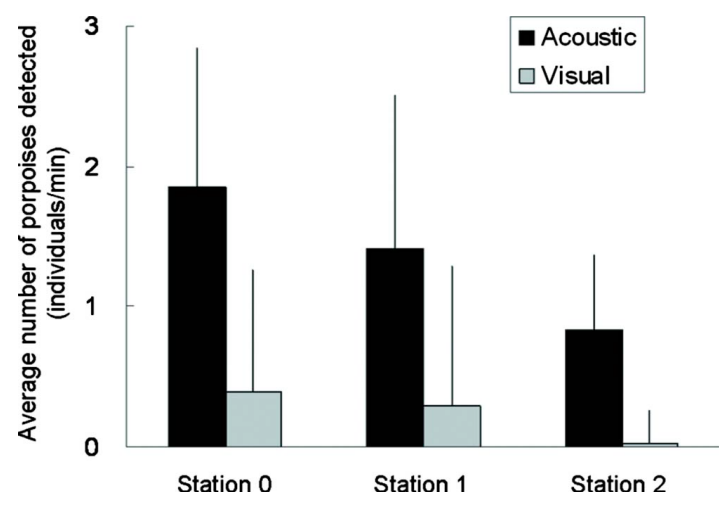

Figure 5.1. Number of individuals detected at three different stations.

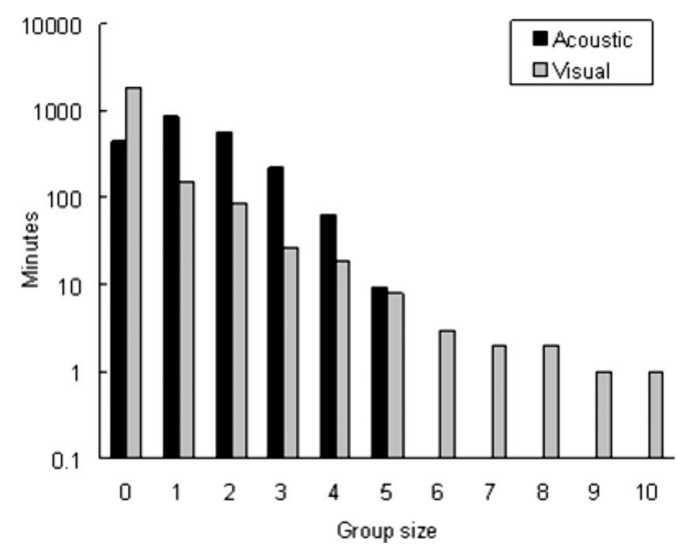

Figure 5.2. Comparison of group sizes. 
Acoustic detection was better at detecting groups with up to five individuals, while visual detection could account for many more individuals (Kimura et al. 2009). These results demonstrate that each technique has strengths and weaknesses, and the pairing of the two may provide more accurate detection depending upon the species of interest and question being addressed.

A study by Clark et al.(2010) compared aerial and acoustic monitoring for right whales and concluded that for simple detection of the animal(s), the acoustic monitoring was more reliable than aerial survey.

It is clear that there is limited information about the relative marine mammal detection efficacy of MMO and PAM methods. However, there is considerable interest in integrating both methods into scientific studies of marine mammal populations and evolving appreciation that, when used jointly, the two methods can provide benefits for industrial activities requiring marine mammal monitoring. For industrial activities, particularly pile driving, what is important is cost-effective marine mammal monitoring that will help provide the operational flexibility needed to meet changing environmental conditions and unexpected construction complications. 


\subsection{Active Acoustics}

The use of active acoustics for sound exposure mitigation is not unprecedented; it is the methodology used by the U.S. Navy to meet the requirements for minimizing the risk to marine mammals during naval exercises. The advantage an active system has over MMOs is the ability to detect animals under the surface, at night, and in other conditions where visibility is limited. The advantages an active system has over passive systems are the ability to detect animals even when they are not vocalizing and the ability to provide localization information important for mitigation. The disadvantages of active systems are limited effective range and area coverage and possible harmful effects on marine life.

Active acoustic monitoring could be appropriate for pile-driving activities if systems operating at low frequencies, like that of the U.S. Navy, were allowed for commercial use and available at a reasonable cost or possibly using higher-frequency systems if theoretical detection ranges were validated in the field.

Active acoustic systems work by transmitting a pulse of sound energy (a ping) and then processing the received echoes. The time delay of the echo gives the range of the reflecting surface. Multiple pings and an array of receivers can be used to form a two- or three-dimensional image. This technology has been used for decades, the most common application being depth finding, or echo sounding, in which echoes from transmitted pings are used to estimate the depth of the sea floor ahead of a boat to avoid grounding. Later, the technology was adapted for locating schools of fish, and "fish finders" are now ubiquitous on both commercial and private fishing boats. Sonar technology has also been applied to the security-related problems of diver detection and mine detection. There are many established providers of sonar equipment in many different form factors.

Recent years have seen an increase in the use of active sonar for marine mammal monitoring. In the United Kingdom and other parts of Europe, active systems have been successfully used to monitor around tidal turbine installations to reduce the risk of blade strike. This detection range may be compared to the requirements for pile-driving activities, in which the necessary detection range is several kilometers. In contrast, for pile-driving activities, the danger to mammals is high levels of sound exposure, and the required mitigation range is on the order of kilometers. That range is difficult to achieve with an active system operating at levels and frequencies considered safe for marine mammals. However, many commercial sonars for navigation and fish-finding operate at frequencies within the auditory range of some mammals and are capable of detecting large targets more than a kilometer distant.

Section 6.1 describes existing systems using active acoustics to detect marine mammals. Section 6.2 provides an analysis of the effectiveness of these types of systems for detecting NARWs.

\subsection{Existing Systems}

A fully automated detection system for marine mammals using active acoustics does not exist, but it is an area of ongoing research. Systems available now require a human operator to monitor the system display and make the final identification of a detected target. The following entries describe active systems that are currently in use or that have been used in the field specifically for marine mammal monitoring. The systems are summarized in Table 6.1. 
Table 6.1. Summary of active acoustic marine mammal monitoring systems.

\begin{tabular}{|c|c|c|c|c|}
\hline Vendor & System & $\begin{array}{l}\text { Frequency } \\
(\mathrm{kHz})\end{array}$ & $\begin{array}{l}\text { Source Level } \\
(\mathrm{dB} \text { re } 1 \mu \mathrm{Pa})\end{array}$ & Use \\
\hline $\begin{array}{l}\text { Scientific } \\
\text { Solutions }\end{array}$ & HF-M3 & $30-40$ & 220 & $\begin{array}{l}\text { Naval exercise sound } \\
\text { exposure mitigation }\end{array}$ \\
\hline FarSounder & FS-SPS & 86 & $\mathrm{NA}^{*}$ & $\begin{array}{l}\text { Ship protection, whale } \\
\text { avoidance }\end{array}$ \\
\hline FarSounder & FS-3 & 60 & NA & $\begin{array}{l}\text { Unmanned Underwater } \\
\text { Vehicle mammal avoidance }\end{array}$ \\
\hline Simrad & EK60 & 38 & NA & $\begin{array}{l}\text { Marine mammal ecological } \\
\text { study }\end{array}$ \\
\hline Simrad & SP90 & $20-30$ & $206,212,218$ & $\begin{array}{l}\text { Killer whale detection } \\
\text { during seismic surveys }\end{array}$ \\
\hline Simrad & SH80 & $110-122$ & 211 & $\begin{array}{l}\text { Killer whale detection } \\
\text { during seismic surveys }\end{array}$ \\
\hline Tritech & $\begin{array}{l}\text { Super SeaKing } \\
\text { DST }\end{array}$ & 300,670 & 210 & $\begin{array}{l}\text { Seal detection at SeaGen } \\
\text { tidal turbine }\end{array}$ \\
\hline Tritech & Gemini SeaTec & 720 & NA & General purpose monitoring \\
\hline Biosonics & DT-X & $\begin{array}{c}38,70,120 \\
200,420 \\
1000\end{array}$ & NA & $\begin{array}{l}\text { Killer whale detection and } \\
\text { tracking }\end{array}$ \\
\hline
\end{tabular}

\subsubsection{Scientific Solutions}

In response to highly publicized whale mass-strandings coincident with naval exercises using lowfrequency active (LFA) sonar, the U.S. Navy is now required to monitor for the presence of marine mammals and to shut down the LFA when the animals are present. The monitoring system, designed and built by Scientific Solutions (Nashua, NH) for this purpose, is an active system called the High Frequency Marine Mammal Monitoring (HF-M3) sonar system. The overall requirement for monitoring was to detect a mammal within, or fast approaching, the zone around the LFA sonar that would be insonified at $180 \mathrm{~dB}$ re $1 \mu \mathrm{Pa}$ (rms) or more. This zone was determined to be approximately $1 \mathrm{~km}$ in horizontal distance from the sonar and within $35 \mathrm{~m}$ above and below the sonar's depth (nominally $122 \mathrm{~m}$ ). An active system was chosen because it is the only monitoring method that can provide reliable coverage at the required depth and in all conditions. The system operates at 30 to $40 \mathrm{kHz}$ with a source level of 220 $\mathrm{dB}$ re $1 \mu \mathrm{Pa}$. This level was chosen based on target strength and background noise estimates as the minimum level that would produce a detectable signal at the required range (Ellison and Stein 2001). The monitoring system itself then produces levels greater than $180 \mathrm{~dB}$ re $1 \mu \mathrm{Pa}$ in the frequency range used by some odontocetes up to $100 \mathrm{~m}$ away. To mitigate harm from the monitoring system, the source level is reduced as an animal is tracked inside the mitigation zone after the LFA sonar is shut down.

The system is personal computer-based, and automated detection is implemented based on rangedependent signal strength thresholding. An operator is required to monitor the display and take action when a marine mammal is approaching the zone. The system has been tested in the water with targets of opportunity and with trained U.S. Navy dolphins to estimate the probability of detection and the false alarm rate. The false alarm rate is low (no exact figure published) because detection is based on multiple 
pings and on a "track;" these criteria eliminate most random false alarms. The theoretical probability of detection for a $10-\mathrm{m}$-long animal (whale calf) is near $100 \%$ at a range of $1 \mathrm{~km}$.

In related work, Scientific Solutions investigated the target strength of gray whales as part of Office of Naval Research-sponsored research into a marine mammal protection system (Lucifredi and Stein 2006). The system would integrate active and passive acoustic detection, and possibly radar, to provide a comprehensive tool for monitoring and protection. The result of this work was a limited proof of concept for using active acoustics to detect and classify gray whales.

Scientific Solutions has more recently developed a marine mammal detection and tracking system for use in conjunction with tidal power. The system is currently being tested in Eastport, Maine, in partnership with Ocean Renewable Power Company. The system consists of multiple nodes operating at 45 to $75 \mathrm{kHz}$ and 90 to $120 \mathrm{kHz}$.

\subsubsection{FarSounder}

Ships under way can strike a whale, causing death to the whale and damage to the ship. FarSounder, Inc. (Warwick, Rhode Island) markets a forward-looking hull-mounted sonar for whale avoidance. The system is in use on commercial vessels and private yachts for whale and other obstacle avoidance. The sonar is a phased array of 96 receiver elements combined with PC-based processing to form a 3-D image. The processing is proprietary, and no details are available on detecting whales specifically. According to the FarSounder website (http://www.farsounder.com), its products have been approved by the National Marine Fisheries Service (NMFS) as safe for marine life. A whale with target strength of $4 \mathrm{~dB}$ can be detected at a maximum range of 700 to $900 \mathrm{ft}$ with the FS-3 system (Zimmerman 2003).

\subsubsection{Simrad}

Active sonar has been used for commercial fishing operations and fishery management for decades. Simrad (Horten, Norway) is a leading provider of these systems, and its echo sounder products have been used for cetacean research (Doksaeter et al. 2009; Bernasconi et al. 2009). In a project sponsored by oil and gas producers, two different Simrad sonar models were tested for detecting killer whales in conjunction with seismic surveys (Knudsen et al. 2008). The detection range of the SP90 $(20-30 \mathrm{kHz})$ was found to be at least $1500 \mathrm{~m}$, and the $\mathrm{SH} 80(110-120 \mathrm{kHz})$ gave reliable detections up to $400 \mathrm{~m}$. Diving whales were detected as well as those at the surface. Vocalizations were also evident in the sonar signal and could be used to automatically classify targets.

\subsubsection{Tritech}

A tidal turbine installation in Northern Ireland used Tritech (Aberdeenshire, Scotland) sonar systems to monitor for the presence of harbor seals near the turbine. Tritech has since used the results of the turbine monitoring trial to develop the Gemini SeaTec Mammal Detection System. The system is composed of a high-frequency $(720-\mathrm{kHz})$ high-resolution imaging sonar and sophisticated software for real-time monitoring. The software color-codes targets onscreen to indicate the probability that a target is a marine mammal and can be programmed to provide a proximity alarm. 
During the tidal turbine trial, the system was validated by comparing detections with visual sightings by an MMO (Keenan et al. 2011). The system detected all the mammals sighted by the observers and also reported additional detections. Those detections may have been false alarms or actual mammals that were not seen by the observers. In any case, the turbine operator, Marine Current Turbines, now relies solely on the active sonar detection system to monitor for seals.

\subsubsection{Biosonics}

The use of active acoustics for the study of fish passage on rivers was pioneered by Biosonics (Seattle, WA). More recently, the Biosonics split-beam echosounder and associated tracking and classification software has been applied to marine mammal monitoring (Munday 2009). A DT-X echosounder was deployed off San Juan Island, Washington, to track killer whales as part of research into developing a monitoring system to study whale behavior around tidal turbines ( $\mathrm{Xu}$ et al. 2012).

\subsection{Expected Performance for NARW Detection during Pile Driving}

The sound exposure levels induced by pile driving could exceed harassment levels as far away as $12 \mathrm{~km}$ for large (4-m diameter) piles, and could induce temporary threshold shift (TTS) in NARWs at ranges up to $254 \mathrm{~m}$ (Stavole 2012). The harassment zone could not be monitored using active acoustics, unless the monitoring system consisted of multiple sensors distributed near the perimeter of the zone. The TTS zone could theoretically be monitored by active acoustics because the effective range of systems operating at $400 \mathrm{kHz}$ and below exceeds $250 \mathrm{~m}$ for a target the size of a right whale. This conclusion was arrived at using the sonar equation and an estimate of the acoustic target strength of a NARW.

The sonar equation gives an estimate of the echo strength received from a target at a given range and frequency

$$
S E=S L+T S+P G-2 T L-(N L-A G)-D T
$$

where $\quad S E=$ Signal Excess - Signal energy above the detection threshold

$S L=$ Source Level - Source (sonar ping) sound pressure level

$T S=$ Target Strength - Acoustic reflectivity of the target

$P G=$ Processing Gain - Gain achieved from signal duration

$T L=$ Transmission Loss - Loss of energy over distance traveled

$N L=$ Noise Level - Background noise spectral energy at the receiver

$A G=$ Array Gain - Gain achieved from beam forming

$D T=$ Detection Threshold - Level above 0 SNR considered a detection.

The range is accounted for in the transmission loss term. Here, the transmission loss is modeled as spherical spreading loss (a conservative model) and absorption loss. The absorption factor in decibels per kilometer depends on environmental characteristics and is frequency dependent, becoming more significant at higher frequencies. The absorption factor was calculated using the simplified model of Ainslie and McComb (1998) using typical ocean environment parameters. The noise level is also frequency dependent; near the surface, where NARWs are often feeding; the dominant source of noise is wind. The signal excess must be greater than zero for the target to be detectable; the range at which the signal excess equals zero is the maximum range for detection. 
The acoustic target strength of an animal depends on the physiological structure of the animal—skin, blubber, etc.- - and the frequency and aspect angle at which it is insonified. There are some field measurements of marine mammals reported in the literature at low frequencies below $100 \mathrm{~Hz}$ (Love 1973; Lucifredi and Stein 2007). The only reported measurements at a higher frequency are in Xu et al. (2012), in which killer whales were measured at $200 \mathrm{kHz}$. The target strength of NARWs was measured at 86 $\mathrm{kHz}$ by Miller and Potter (2001) and the average target strength was between -4.8 and $-1.4 \mathrm{~dB}$. The results of all the reports suggest that a broadside aspect produces the strongest return and a tail-on aspect produces the weakest.

Due to a lack of empirical data, the broadside target strength of a mammal is usually modeled using the equation from Love (1971) for fish (Parvin et al. 2007; Ellison and Stein 2001), even though the equation is only valid for

$$
1 \leq \frac{L}{\lambda} \leq 130
$$

where $L$ is the length of the fish in meters and $\lambda$ is the wavelength of the source. This means that for a $15-\mathrm{m}$ animal, the model is valid up to $13 \mathrm{kHz}$. Laboratory measurements of the target strength of a $2.2-\mathrm{m}$ dolphin were found to differ significantly from the Love model predictions at frequencies above $23 \mathrm{kHz}$ (Au 1996). The model predicts that target strength increases with frequency, but the measurements showed a drop of roughly $15 \mathrm{~dB}$ between 25 and $45 \mathrm{kHz}$, beyond which the strength leveled out. Figure 6.1 shows the model-predicted values for a $10-\mathrm{m}$ and a $15-\mathrm{m}$ animal and the reported measurements of NARWs.

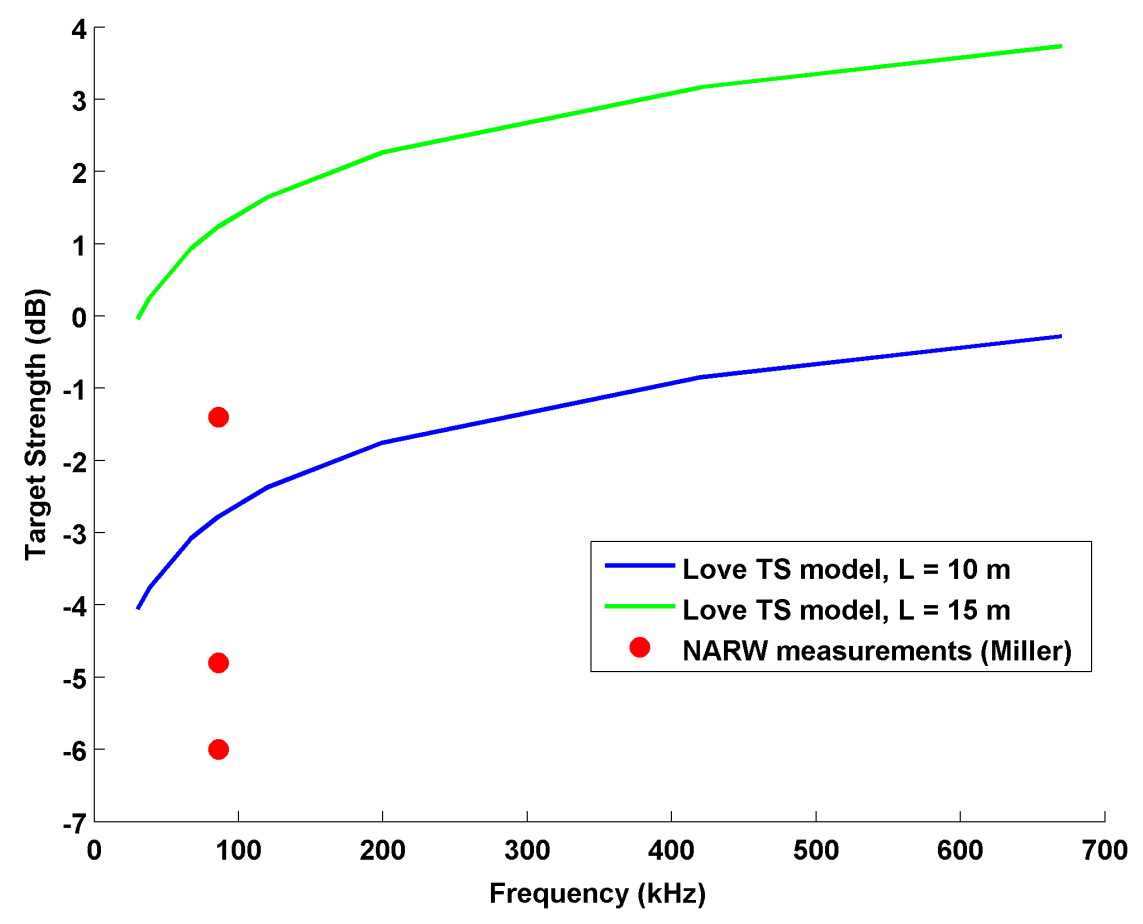

Figure 6.1. The predicted target strength of an animal using the model of Love (1971) although the model is not valid in this frequency range. 
To determine the effective range of sonar for detecting NARWs, the target strength was assumed to be $-4 \mathrm{~dB}$ at all frequencies. This is consistent with the few available field measurements and with the finding of $\mathrm{Au}$ (1996), that the target strength did not increase with frequency. Clearly, this is a simplifying assumption, and the resulting analysis must be viewed with caution. It should be noted that some of the killer whale measurements at $200 \mathrm{kHz}$ were as low as $-48 \mathrm{~dB}$ from what was likely a tail-on aspect; the measurements were around -7 to $-10 \mathrm{~dB}$ for what was assumed to be a broadside aspect. The results of the sonar equation predictions for effective range as a function of frequency are shown in Figure 6.2.

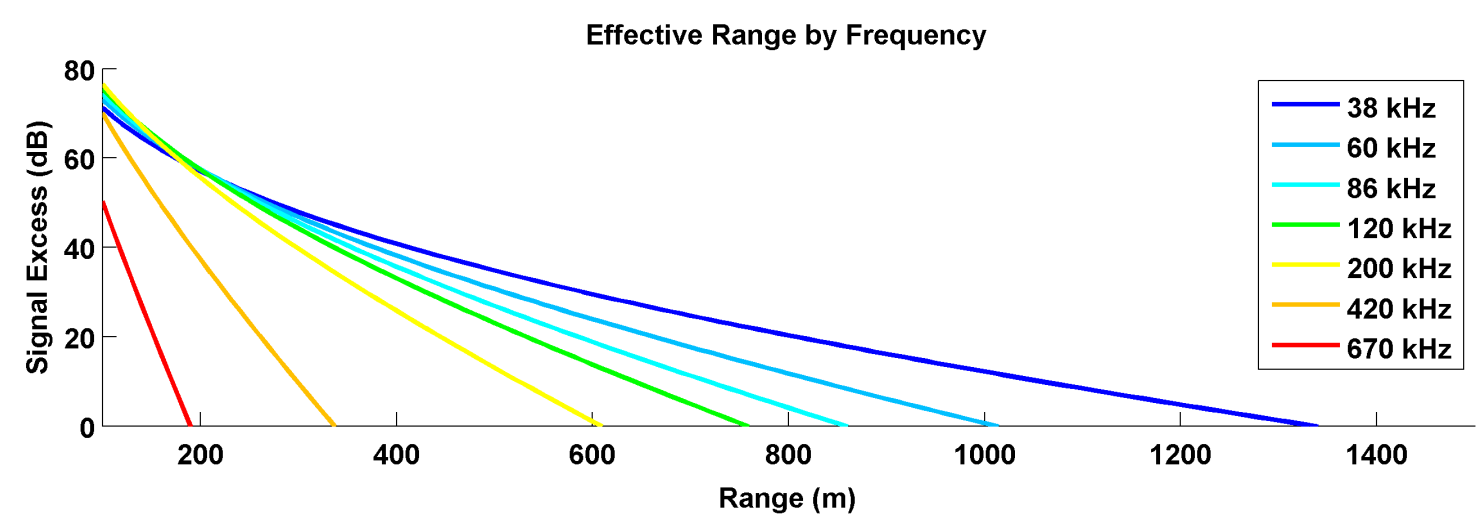

Figure 6.2. The effective range of active sonar for detecting a NARW estimated using the sonar equation. A signal excess of zero indicates the maximum range.

Model parameters are as listed:

- $S L=210 \mathrm{~dB}$ re $1 \mu \mathrm{Pa}$

- $T S=-4 \mathrm{~dB}$, conservative estimate

- $P G=10 \log t, t=0.1 \mathrm{sec}$, ping signal duration

- $T L=20 \log r+\alpha(f) r \mathrm{~dB}$, one-way transmission loss

- $S=34$ ppt, salinity (Ainslie and McComb 1998)

- $T=4^{\circ} \mathrm{C}$, water temperature

- $p H=7.7$, water acidity (Ainslie and McComb 1998)

- $N L=40+10 \log w^{2} /\left(1+f^{5 / 3}\right)$, wind speed $\mathrm{w}=10$ knots

- $A G=0$ (ignore beamforming gains)

- $D T=12 \mathrm{~dB}$.

The sonar equation is useful for calculating the relative theoretical performance of systems operating at different frequencies, all else being equal. Another factor affecting performance that is more difficult to quantify is gains in the probability of detection because of signal processing. There are sonar image processing techniques for image enhancement and object detection (Trucco et al. 2009) that can be applied to the raw echo data of any system. Software such as Echoview (http://www.echoview.com) is commercially available for custom sonar data processing. 


\subsection{Initiation of Analysis for Exposure of NARW to Pile-Driving Sound}

This section provides a first look at the analyses needed to determine the risk to NARWs from construction operations for installation of offshore wind turbines. Considerable additional analyses are needed that specific the location and timing of installation, as well as the specific type of construction activity, size of piles to be used, and methodology proposed for detecting behavioral changes in the NARWs.

Specific operations such as pile-driving that occur during construction of offshore wind turbines create impulse sound at levels near the piles high enough to potentially affect the hearing (TTS or permanent threshold shift) of exposed marine mammals. There is no evidence that NARWs will respond to pile-driving sound and avoid high levels of exposure. NARWs may have difficulty localizing sound in part because of the way sound propagates in the ocean (Nowacek et al. 2004).

Of interest is the likelihood that NARWs might be exposed to sounds like pile driving during wind farm construction. Assessment of the risk to NARWs of exposure to impulsive sound must consider the likelihood that NARWs will occur at wind farm sites and, if they occur, the sound exposure they are likely to experience. The locations of 24,474 NARW sightings were compiled from various sources and entered into ArcGIS. As an initial step in analysis to estimate probable exposure to pile-driving sound by NARWs, we computed the radial distance out to $21 \mathrm{~km}$ from the center of the four potential wind farm sites for sighted NARWs and, in addition, the number of NARWs sighted within the boundaries of the proposed wind farm sites (Table 7.1).

Table 7.1. The number of NARWs sighted within radial distances from the center of proposed wind farm development sites off the Mid-Atlantic coast. Also shown is the percentage of sightings out of the total data set of 24,474 NARW sightings within the considered radial distances.

\begin{tabular}{|c|c|c|c|c|c|c|c|c|}
\hline \multirow{2}{*}{$\begin{array}{c}\text { Radial } \\
\text { Distance from } \\
\text { Wind Site } \\
\text { Center }\end{array}$} & \multicolumn{2}{|c|}{$\begin{array}{l}\text { Wind Farm } 1 \\
\text { New Jersey }\end{array}$} & \multicolumn{2}{|c|}{$\begin{array}{c}\text { Wind Farm } 2 \\
\text { Delaware }\end{array}$} & \multicolumn{2}{|c|}{$\begin{array}{c}\text { Wind Farm } 3 \\
\text { Maryland }\end{array}$} & \multicolumn{2}{|c|}{$\begin{array}{c}\text { Wind Farm } 4 \\
\text { Virginia }\end{array}$} \\
\hline & $\begin{array}{c}\text { Cumulative } \\
\text { Number of } \\
\text { NARW }\end{array}$ & $\begin{array}{c}\text { Cumulative } \\
\% \text { of } \\
\text { NARW }\end{array}$ & $\begin{array}{c}\text { Cumulative } \\
\text { Number of } \\
\text { NARW }\end{array}$ & $\begin{array}{c}\text { Cumulative } \\
\% \text { of } \\
\text { NARW }\end{array}$ & $\begin{array}{c}\text { Cumulative } \\
\text { Number of } \\
\text { NARW }\end{array}$ & $\begin{array}{c}\text { Cumulative } \\
\% \text { of } \\
\text { NARW }\end{array}$ & $\begin{array}{c}\text { Cumulative } \\
\text { Number of } \\
\text { NARW }\end{array}$ & $\begin{array}{c}\text { Cumulative } \\
\% \text { of } \\
\text { NARW }\end{array}$ \\
\hline 0.01 & 14 & 0.057204 & 2 & 0.008172 & 0 & 0 & 0 & 0 \\
\hline 0.05 & 14 & 0.057204 & 2 & 0.008172 & 0 & 0 & 0 & 0 \\
\hline 0.1 & 14 & 0.057204 & 2 & 0.008172 & 0 & 0 & 0 & 0 \\
\hline 0.3 & 14 & 0.057204 & 2 & 0.008172 & 0 & 0 & 0 & 0 \\
\hline 0.5 & 14 & 0.057204 & 2 & 0.008172 & 0 & 0 & 0 & 0 \\
\hline 0.8 & 14 & 0.057204 & 2 & 0.008172 & 0 & 0 & 0 & 0 \\
\hline 1 & 14 & 0.057204 & 2 & 0.008172 & 0 & 0 & 0 & 0 \\
\hline 3 & 18 & 0.073547 & 4 & 0.016344 & 0 & 0 & 0 & 0 \\
\hline 6 & 21 & 0.085805 & 4 & 0.016344 & 0 & 0 & 0 & 0 \\
\hline 9 & 21 & 0.085805 & 4 & 0.016344 & 0 & 0 & 0 & 0 \\
\hline 12 & 25 & 0.102149 & 4 & 0.016344 & 0 & 0 & 0 & 0 \\
\hline 15 & 27 & 0.110321 & 5 & 0.02043 & 0 & 0 & 6 & 0.024516 \\
\hline 18 & 25 & 0.102149 & 6 & 0.024516 & 3 & 0.012258 & 6 & 0.024516 \\
\hline 21 & 28 & 0.114407 & 8 & 0.032688 & 5 & 0.02043 & 6 & 0.024516 \\
\hline
\end{tabular}


This brief analysis, provided for illustrative purposes only, shows that very few of 24,474 sightings of NARWs occurred within $21 \mathrm{~km}$ of the centers of prospective wind farms. However, at this early stage, this analysis may indicate more about the quality of the NARW observations available for analysis than about the occurrence of NARWs at wind farm locations. Additional analyses including any other available data are necessary before any conclusions about the likely occurrence of NARWs in areas that may be impacted by pile-driving sound are possible. Better assessment of the likely occurrence of NARWs near potential pile-driving sites is important when considering the design of monitoring and mitigation strategies. Such analysis is also valuable during the design of marine mammal call detection and classification elements of passive acoustic marine mammal monitoring systems and for other potential monitoring system elements such as active acoustic and visual monitoring. 


\subsection{Monitoring and Mitigation Template}

Installation of commercial-scale wind farms requires long periods of construction, potentially stretching into years. The Cape Wind development environmental impact statement estimates a construction period of multiple years during which approximately 130 large diameter steel shell piles will be driven, wind turbines installed, and transmission lines and other infrastructure put in place (MMS 2009). In reviewing the project, regulators noted that suggested monitoring and mitigation plans did not adequately address the ability to detect the presence of marine mammals, particularly NARWs, within construction exclusion zones during darkness, fog, inclement weather, and other circumstances that would limit observer ability to visually detect the animals. The NMFS in its review suggested the use of acoustics and other sensing modalities as elements of monitoring strategies that could potentially improve the overall effectiveness of monitoring (NMFS 2010).

\subsection{Monitoring Requirements and Capabilities}

Large-scale construction of offshore wind farms will require monitoring for the presence of marine mammals at times when the effectiveness of visual observations is limited. These construction activities require the use of specialized equipment and crews that are expensive to mobilize and retain on site. The economic viability of offshore wind farms depends in large part on the costs of their construction. Efficient use of specialized equipment typically translates into completing as much work as possible when the equipment is on site; equating to working as many hours as possible per day.

Recently, monitoring for marine mammals at the MCT SeaGen tidal turbine in Northern Ireland transitioned from the use of MMOs to the application of active acoustics as the primary monitoring modality, using Tritech rotating acoustic cameras. This action followed a period during which marine mammal monitoring was conducted using both active acoustics and MMOs. During this time, studies were conducted to assess the strengths and weaknesses of both monitoring methods and the performance of active acoustic monitoring to meet project requirements.

Large-scale wind farm construction has similarities to long-term monitoring at tidal power projects. For both, the period during which monitoring is required to meet permit requirements is long enough to allow assessment of the performance of acoustic and other monitoring tools compared to visual monitoring techniques, and to develop monitoring strategies that permit the option of construction activities, such as pile driving, during times in which visual monitoring is not feasible.

The objective of monitoring during wind farm construction is to avoid exposing marine mammals to levels of sound during construction activities such as pile driving that could damage their health or cause changes in behavior that could, in other ways, affect their health. Pile driving can produce high levels of impulsive sound that may propagate considerable distances from the pile and may not attenuate to background levels for several kilometers from the pile. Regulatory actions to date are aimed at preventing exposure of marine mammals to sounds greater than $180 \mathrm{~dB}$ ref $\mu \mathrm{Pa}$ (NFMS 2010). Sound propagation modeling and measurements during pile driving indicate that sound levels greater than $180 \mathrm{~dB}$ are unlikely to occur beyond $500 \mathrm{~m}$ of the location $\mathrm{n}$ which 5-m-diameter steel shell piles are driven; these dimensions would include planned piling for the Cape Wind turbine foundations (BOEMRE 2009). In its 2010 Biological Opinion, the NMFS specifies a 750-m radius exclusion zone around a pile being driven; monitoring by MMOs is required to begin $1 \mathrm{~h}$ prior to initiation of driving and to extend 
through completion of driving of the pile. A 750-m radius exclusion zone is within the range of distance that may be monitored in whole or part by a variety of active and passive acoustic methods, as well as by visual methods.

\subsection{Planning for Monitoring and Mitigation}

The technical and logistic complexity of marine construction requires extensive planning prior to initiation of construction activity. During this planning process, decisions about the location of piles, the sequence of their installation, procurement of specialized equipment, and numerous other logistics are scheduled, and the final costs estimated. It is possible at the same time to identify the times and locations where extended work hours would be most beneficial to construction activities and to assess the benefits of being able to continue construction through periods of inclement weather, darkness, and other conditions when visual marine mammal monitoring is not possible. Integration of monitoring and mitigation planning into the overall construction planning for offshore wind farm installation is the critical first step into designing monitoring and mitigation components that will be facilitate permitting of wind farms.

The development of active and passive acoustic systems for detection, classification, and localization of marine mammals is moving forward very quickly. Passive acoustic systems are now commonly used in conjunction with MMOs to monitor for the presence of marine mammals during seismic surveys conducted from moving vessels. Fixed-location activities, such as pile driving, support the use of active acoustic devices that are generally not available for deployment and use from moving vessels. Fixedlocation active acoustic systems are now used as standalone monitoring systems for protection of marine mammals at tidal power projects. The second critical step in designing a monitoring and mitigation plan is to identify the scope of monitoring to be conducted and the appropriate mix of visual, acoustic, and other monitoring modalities.

The occurrence of marine mammals in specific locations follows behavior patterns related to life functions such as migration, breeding, calving, and feeding that are driven by physical and biological environmental factors. The size of populations, activity levels, response to anthropogenic sound and other factors, combined with behavior patterns, determine the likelihood that marine mammals will occur at a wind farm construction site. The third critical step in design and implementation of monitoring and mitigation for wind farm construction is to evaluate the likelihood that marine mammals of interest will occur in a construction site and the most likely behaviors they will exhibit while at the site.

The fourth critical step in the process is the creation of an integrated monitoring and mitigation plan that will bring together information about construction schedules and times that can be extended through the application of appropriate monitoring techniques; capabilities of visual, acoustic, and other marine mammal monitoring modalities; and the likely occurrence of NARWs in the construction zone. The outcome of the plan will be the specification of the monitoring tools tailored to complying with permits in the most efficient and cost-effective manner possible. 


\subsection{Conclusion}

Development of marine mammal monitoring and mitigation alternatives for pile driving and other construction activities that occur during wind farm installation can draw strongly from methods and processes used for seismic surveys. These techniques are being supplemented by ongoing research into the development and application of integrated visual and acoustic methods for estimating marine mammals abundance and behavior. The challenge of designing monitoring and mitigation for NARW protection during offshore wind farm installation includes: 1) understanding the distribution of the animals at sea throughout the year in order to determine the likely intersection of the NARWs and the construction activities; 2) developing performance specifications for marine mammal monitoring systems that meet industry needs to comply with permitting requirements during turbine installation; and 3) deploying those systems at a cost that is acceptable to the industry. It is also important that industry accept alternative methods for construction of wind farms, and integrate planning for marine mammal monitoring and mitigation into construction planning as early as possible for activities such as pile driving that have the potential of generating high levels of sound that could impact the health of NARWs and other marine mammals. 



\subsection{References}

Ainslie MA and JG McColm. 1998. "A simplified formula for viscous and chemical absorption in sea water." The Journal of the Acoustical Society of America 103(3):1671-1672.

Au W. 1996. "Acoustic reflectivity of a dolphin.” Journal of Acoustical Society of America 99(6):3844-3848.

Bailey H, B Senior, D Simmons, J Rusin, G Picken, and PM Thompson. 2010. “Assessing underwater noise levels during pile-driving at an offshore windfarm and its potential effects on marine mammals." Marine Pollution Bulletin 60(6):888-897.

Barkaszi MJ, M Butler, R Compton, A Unietis, and B Bennet. 2012. "Seismic survey mitigation measures and marine mammal observer reports." OCS Study BOEM 2012-015, U.S. Department of the Interior, Bureau of Ocean Energy Management, Gulf of Mexico OCS Region, New Orleans, Louisiana.

Barton CJS, R Jaques, and M Mason. 2008. Identification of Potential Utility of and Collation of Existing Marine Mammal Observer Data. Final report, RSK Environment Ltd., Cheshire, United Kingdom to Joint Industry Programme, Sound and Marine Life Programme.

Baumgartner MF, Mate BR (2003) Summertime foraging ecology of North Atlantic right whales. Mar Ecol Prog Ser 264:123-135

Bernasconi M, R Patel, L Nøttestad, FR Knudsen, and AS Brierley. 2009. "Use of active sonar for cetacean conservation and behavioral-ecology studies: A paradox?" Proceedings of the Institute of Acoustics 31(1).

Bingham G. 2011. "Status and Applications of Acoustic Mitigation and Monitoring Systems for Marine Mammals." Paper presented at the Workshop Proceedings, November 17-19, 2009, Boston, Massachusetts.

BOEMRE - Bureau of Energy Management, Regulation and Enforcement. 2009. "Status and Applications of Acoustic Mitigation and Monitoring Systems for Marine Mammals." Workshop on the Status and Applications of Acoustic Mitigation and Monitoring Systems for Marine Mammals, November 17, 2009, Boston, Massachusetts.

Brower H, CW Clark, M Ferguson, J Gedamke, B Southall, and R Suydam. 2011. Expert Panel Review of Monitoring Protocols in Applications for Incidental Harassment Authorizations Related to Oil and Gas Exploration in the Chukchi and Beaufort Seas, 2011: Statoil and ION Geophysical. National Oceanographic and Atmospheric Adminstration, Peer-review Panel Report 2011, March 9, 2011, Anchorage, Alaska. Accessed October 3, 2012, at http://www.nmfs.noaa.gov/pr/pdfs/permits/openwater/peer_review_report2011.pdf.

Clapham, P.J., (ed.) 2002. Report of the working group on survival estimation for North Atlantic right whales. Available from the Northeast Fisheries Science Center, 166 Water Street, Woods Hole, MA 02543.

Clark, C. W. 1982. The acoustic repertoire of the southern right whale: A quantitative analysis. Animal Behavior 30:1060-1071. 
Clark, C.W. 1983. Acoustic communication and behavior of the southern right whale. Pages 163-198 in R. S. Payne, ed. Behavior and communication of whales. Westview Press, Boulder, CO.

Clark CW, MW Brown, and P Corkeron. 2010. "Visual and acoustic surveys for North Atlantic right whales, Eubalaena glacialis, in Cape Cod Bay, Massachusetts, 2001-2005: Management implications." Marine Mammal Science 26(4):837-854. doi:10.1111/j.1748-7692.2010.00376.x.

Clark CWand PJ Clapham. 2004. "Acoustic monitoring on a humpback whale (Megaptera novaeangliae) feeding ground shows continual singing into late spring." Proceedings of the Royal Society of London B 271(1543):1051-1057.

Commander of the U.S. Pacific Fleet and Third Fleet. 2007. Final Request for Letter of Authorization for the Incidental Harassment of Marine Mammals Resulting from Navy Training Operations Conducted within the Hawaii Range Complex. Office of Protected Resources, National Marine Fisheries Service, National Oceanic and Atmospheric Administration, Silver Spring, Maryland.

Cupka D and M Murphy. 2005. North Atlantic Right Whale (Eubalaena glacialis). DNR:

Comprehensive Wildlife Conservation Strategy, 2012. http://www.dnr.sc.gov/cwcs/.

Doksæter L, OR Godø, E Olsen, L Nøttestad, and R Patel. 2009. "Ecological studies of marine mammals using a seabed-mounted echosounder." ICES Journal of Marine Science: Journal du Conseil 66(6):1029-1036.

EESI - Environmental and Energy Study Institute. 2010. Fact Sheet: Offshore Wind Energy. Accessed October 4, 2012, at http://www.eesi.org/files/offshore_wind_101310.pdf.

Ellison WT and P Stein. 2001. SURTASS LFA High Frequency Marine Mammal Monitoring (HF/M3) Sonar: System Description and Test \& Evaluation. Marine Acoustics, Inc. and Scientific Solutions, Inc., http://www.surtass-lfa-eis.com/docs/HF-M3\%20Ellison\%20Report\%202-4a.pdf.

Endangered Species Act of 1973. 1973. Public Law 93-205, as amended, 16 USC 1531 et seq.

Erbe C. 2002. Hearing Abilities of Baleen Whales. DRDC Atlantic CR 2002-065, Defence R\&D

Canada. http://cradpdf.drdc-rddc.gc.ca/PDFS/unc09/p519661.pdf.

Firestone J, SB Lyons, C Wang, and JJ CorbettJ. 2008. "Statistical modeling of North Atlantic right whale migration along the mid-Atlantic region of the eastern seaboard of the United States." Biological Conservation 141(1):221-232. doi:10.1016/j.biocon.2007.09.024.

Greene CR, NS Altman, and WJ Richardson. 1999. "The influence of seismic survey sounds on bowhead whale calling rates." Journal of Acoustical Society of America 106(2):280.

Gillespie, D. and Leaper, R. 2001. Report of the Workshop on Right Whale Acoustics: Practical Applications in Conservation, Woods Hole, 8-9 March 2001. Paper SC/53/BRG2 presented to the IWC Scientific Committee, July 2001, London (unpublished). 23pp. [Paper available from the Office of this Journal]. 
Halvorsen MB, BM Casper, CM Woodley, TJ Carlson, and AN Popper. 2012. "Threshold for Onset of Injury in Chinook Salmon from Exposure to Impulsive Pile Driving Sounds." PLoS ONE 7(6):e38968. doi:10.1371/journal.pone.0038968.

The Jones Act, 46 U.S.C.A. $\S 688$, et seq

Keenan G, C Sparling, H Williams, and F Fortune. 2011. SeaGen Environmental Monitoring Programme Final Report. Marine Current Turbines, http://seageneration.co.uk/files/SeaGenEnvironmental-Monitoring-Programme-Final-Report.pdf.

Kenney RD, MAM Hyman, RE Owen, GP Scott, and HE Winn. 1986. "Estimation of Prey Densities Required by Western North Atlantic Right Whales.” Marine Mammal Science 2(1):1-13. doi:10.1111/j.1748-7692.1986.tb00024.x.

Kenney RD, HE Winn, and MC Macaulay. 1995. "Cetaceans in the Great South Channel, 1979-1989: Right whale (Eubalaena glacialis)." Continental Shelf Research 15(4-5):385-414. doi:10.1016/02784343(94)00053-p.

Kimura S, T Akamatsu, K Wang, D Wang, S Li, S Dong, and N Arai. 2009. "Comparison of stationary acoustic monitoring and visual observation of finless porpoises." The Journal of the Acoustical Society of America 125(1):547-553.

Knowlton AR and SD Kraus. 2001. "Mortality and Serious Injury of Northern Right Whales (Eubalaena glacialis) in the Western North Atlantic Ocean." Journal of Cetacean Research and Management 2:193-208.

Knudsen FR, OB Gammelsæter, PH Kvadsheim, and L Nøttestad. 2008. "Evaluation of fisheries sonar for whale detection in relation to seismic survey operations." Bioacoustics 17(1-3):327-328.

Ljungblad DK, B Würsig, SL Swartz, and JM Keene. 1988. "Observations on the behavioral responses of bowhead whales (Balaena mysticetus) to active geophysical vessels in the Alaskan Beaufort Sea." Arctic 41(3):183-194.

Love RH. 1971. "Dorsal-Aspect Target Strength of an Individual Fish." The Journal of the Acoustical Society of America 49(3B):816-823.

Love RH. 1973. "Target strengths of humpback whales Megaptera novaeangliae." The Journal of the Acoustical Society of America 54(5):1312-1315.

Lucifredi I and PJ Stein. 2006. "Integrated Marine Mammal Monitoring and Protection System (IMAPS): Gray Whale Target Strength Measurements and the Analysis of the Back-Scattered Response." Paper presented at the OCEANS 2006, September 18-21, 2006.

Lucifredi I and PJ Stein. 2007. "Gray whale target strength measurements and the analysis of the backscattered response." The Journal of the Acoustical Society of America 121(3):1383-1391.

Marine Mammal Protection Act of 1972 as Amended. 2007. 16 USC 1361 et seq. 
Matthews JN, S Brown, D Gillespie, M Johnson, R McLanaghan, A Moscrop, D Nowacek, R Leaper, T Lewis, and P Tyack. 2001. "Vocalisation rates of the North Atlantic right whale (Eubalaena glacialis)." Journal of Cetacean Research and Management 3(3):271-282.

Mellinger D and J Barlow. 2003. Future Directions for Acoustic Marine Mammal Surveys: Stock Assessment and Habitat Use: Report of a Workshop Held in La Jolla, California, 20-22 November 2002. U.S. Department of Commerce, National Oceanic and Atmospheric Administration, Pacific Marine Environmental Laboratory, Seattle, Washington.

Mellinger DK, Nieukirk SL, Matsumoto H, Heimlich SL, Dziak RP, Haxel J, Fowler M (2007) Seasonal occurrence of North Atlantic right whale (Eubalaena glacialis) vocalizations at two sites on the Scotian Shelf. Mar Mamm Sci 23: 856-867

Miller JH and DC Potter. 2001. "Active high frequency phased-array sonar for whale shipstrike avoidance: target strength measurements. "Paper presented at the OCEANS, 2001. MTS/IEEE Conference and Exhibition. http://ieeexplore.ieee.org/xpls/abs_all.jsp?arnumber=968324\&tag=1.

MMS - Minerals Management Service. 2009. Cape Wind Final Environmental Impact Statement. MMS EIS-EA OCS Publication No. 2008-040, U.S. Department of the Interior, Washington, D.C.

Munday E. 2009. "Using Sonar to Investigate Interactions Between Marine Life, Subsea Turbines." Sea Technology Magazine September 2009.

Munger LWS, S Moore, and J Hildebrand. 2008. "North Pacific Right Whale (Eubalaena japonica) Seasonal and Diel Calling Patterns from Long-Term Acoustic Recordings in the Southeastern Bering Sea, 2000-2006." Marine Mammal Science 24(4):795-814.

NMFS - National Marine Fisheries Service. 2010. National Marine Fisheries Service Endangered Species Act Section 7 Consultation Biological Opinion. Bureau of Ocean Energy Management, Regulation and Enforcement, U.S. Army Corps of Engineers, and U.S. Environmental Protection Agency, Gloucester MA. http://www.nero.noaa.gov/prot_res/section7/MMSsignedBOs/NMFS\%20CapeWindBiOp123010.pdf

Nowacek DP, MP Johnson, and PL Tyack. 2004. "North Atlantic right whales (Eubalaena glacialis) ignore ships but respond to alerting stimuli." Proceedings of the Royal Society of London B 271:227231.

NTL-2012-Joint-G02. 2012. "Implementation of Seismic Survey Mitigation Measures and Protected Species Observer Program.” In BOEM (Ed.), (Vol. OMB control \# 1010-0151): Notice to Lessees and Operators, United States Department of the Interior, Bureau of Ocean Energy Management (BOEM) Bureau of Safety and Environmental Enforcement (BSEE), Gulf Of Mexico Outer Continental Shelf (OCS) Region.

“Offshore Wind Energy: Fact Sheet”. Environmental and Energy Studies (2010).

Pace III, RM, and RL Merrick. 2008. "Northwest Atlantic Ocean Habitats Important to the Conservation of North Atlantic Right Whales (Eubalaena glacialis)." Northeast Fish Science Center Reference Document 08-07, 24 pp. Accessed October 4, 2012, at http://nefsc.noaa.gov/publications/crd/crd0807/. 
Parks S, A Searby, A Célérier, M Johnson, D Nowacek, and P Tyack. 2011. "Sound production behavior of individual North Atlantic right whales: Implications for passive acoustic monitoring." Endangered Species Research 15(1):63-76. doi:10.3354/esr00368.

Parks SE, DR Ketten, JT O’Malley, and J Arruda. 2007. “Anatomical predictions of hearing in the North Atlantic right whale." The Anatomical Record 290(6):734-744.

Parks SE and PL Tyack. 2005. "Sound production by North Atlantic right whales (Eubalaena glacialis) in surface active groups." The Journal of the Acoustical Society of America 117(5):3297-3306.

Parvin SJ, E Harland, and JR Nedwell. 2007. The Target Strength of marine mammals, and estimated performance of Active Acoustic Monitoring systems. Subacoustech Report No. 565R0608, Hampshire, United Kingdom.

Patenaude NJ, WJ Richardson, MA Smultea, WR Koski, GW Miller, B Würsig, and CR Greene Jr. 2002. "Aircraft sound and disturbance to bowhead and beluga whales during spring migration in the Alaskan Beaufort Sea." Marine Mammal Science 18(2):309-335.

Pettis, Heather. North Atlantic Right Whale Consortium Annual Report Card (November 2010).

Richardson WJ, KJ Finley, GW Miller, RA Davis, and WR Koski. 1995a. "Feeding, social and migration behavior of bowhead whales, Balaena mysticetus, in Baffin Bay vs. The Beaufort Sea - regions with different amounts of human activity." Marine Mammal Science 11(1):1-45. doi:10.1111/j.17487692.1995.tb00272.x.

Richardson WJ, CR Greene, Jr., CI Malme, and DH Thompson. 1995b. Marine Mammals and Noise. Academic Press, Inc., San Diego, California.

Richardson WJ, GW Miller and CR Greene, Jr. 1999. "Displacement of migrating bowhead whales by sounds from seismic surveys in shallow waters of the Beaufort Sea." The Journal of the Acoustical Society of America 106(4):2281-2281.

Richardson WJ, B Wursig, and CR Greene, Jr. 1986. "Reactions of bowhead whales, Balaena mysticetus, to seismic exploration in the Canadian Beaufort Sea." The Journal of the Acoustical Society of America 79(4):1117-1128.

Rosenbaum HC, RL Brownell, Jr., MW Brown, C Schaeff, V Portway, BN White, S Malik, LA Pastene, NJ Patenaude, CS Baker, M Goto, PB Best, PJ Clapham, P Hamilton, M Moore, R Payne, V Rowntree, CT Tynan, JL Bannister and R DeSalle. 2000. "World-wide genetic differentiation of Eubalaena:

Questioning the number of right whale species." Molecular Ecology 9(11):1793-1802.

SEIC - Sakhalin Energy Investment Company. 2007. Marine Mammal Observer Programe, SEIC MMO Programma Effectiveness. Western Gray Whale Advisory Panel, 3rd meeting, WGWAP 3/INF.20-REV. Accessed October 4, 2012, at http://cmsdata.iucn.org/downloads/marine_mammal_observer_program.pdf.

Southall BL, AE Bowles, WT Ellison, JJ Finneran, RL Gentry, CR Greene, Jr., D Kastak, DR Ketten, JH Miller, PE Nachtigall, WJ Richardson, JA Thomas, and PL Tyack. 2007. "Marine mammal noise exposure criteria: Initial scientific recommendations.” Aquatic Mammals 33(4):121. 
Southall BL and DP Novacek. 2009 . "Acoustics in marine ecology: innovation in technology expands the use of sound in ocean science." Marine Ecology Progress Series 395:1-3. doi:10.3354/meps08393.

Stavole, Jessica. 2012. Acoustic effects of pile-driving on the North Atlantic Right Whale. PNNL Report, Seattle, WA.

Stone C and M Tasker. 2006. "The effects of seismic airguns on cetaceans in UK waters." Journal of Cetacean Research and Management 8(3):255-263.

Stone CJ. 2000. Cetacean observations during seismic surveys in 1998. Joint Nature Conservation Committee, Report No. 301, Aberdeen, United Kingdom. http://carolynbarton.co.uk/jncc301.pdf.

Trucco A, M Garofalo, S Repetto, and G Vernazza. 2009. "Processing and Analysis of Underwater Acoustic Images Generated by Mechanically Scanned Sonar Systems.” IEEE Transactions on Instrumentation and Measurement 58(7):2061-2071.

Vanderlaan ASM, AE Hay, and CT Taggart. 2003. "Characterization of North Atlantic right-whale (Eubalaena glacialis) sounds in the Bay of Fundy." IEEE Journal of Oceanic Engineering 28:164-173.

Waring G, E Josephson, K Maze-Foley, and Rosel (eds.). 2012. U.S. Atlantic and Gulf of Mexico Marine Mammal Stock Assessments -- 2011. NOAA Technical Memorandum NMFS NE 221, 319 p. Available from: National Marine Fisheries Service, 166 Water Street, Woods Hole, MA 02543-1026, or online at http://www.nefsc.noaa.gov/nefsc/publications/.

(http://www.nefsc.noaa.gov/publications/tm/tm221/)

Weinrich M and C Pekarcik. 2007. The effectiveness of dedicated observers in reducing risks of marine mammal collisions with ferries: A test of the technique. Report \#SC/59/BC11, The Whale Center of New England, Gloucester, Massachusetts.

Weller DW, YV Ivashchenko, GA Tsidulko, AM Burdin, and RL Brownell, Jr. 2002. "Influence of seismic surveys on western gray whales off Sakhalin Island, Russia in 2001." Publications, Agencies and Staff of the U.S. Department of Commerce. Paper 73. Accessed October 4, 2012, at http://digitalcommons.unl.edu/usdeptcommercepub/73.

Werth AJ. 2012. "Hydrodynamic and Sensory Factors Governing Response of Copepods to Simulated Predation by Balaenid Whales." International Journal of Ecology 2012:13. doi:10.1155/2012/208913.

Würsig B, EM Dorsey, WJ Richardson, and RS Wells. 1989. "Feeding, aerial, and play behavior of the bowhead whale, Balaena mysticetus, summering in the Beaufort Sea." Aquatic Mammals 15:27-37.

Xu J, ZD Deng, TJ Carlson, and B Moore. 2012. "Target Strength of Southern Resident Killer Whales (Orcinus orca): Measurement and Modeling." Marine Technology Society Journal 46(2):74-84.

Zimmerman MJ. 2003. A 3D, Forward-Looking, Phased Array, Obstacle Avoidance Sonar for Autonomous Underwater Vehicles. FarSounder, Inc., Providence, Rhode Island. 



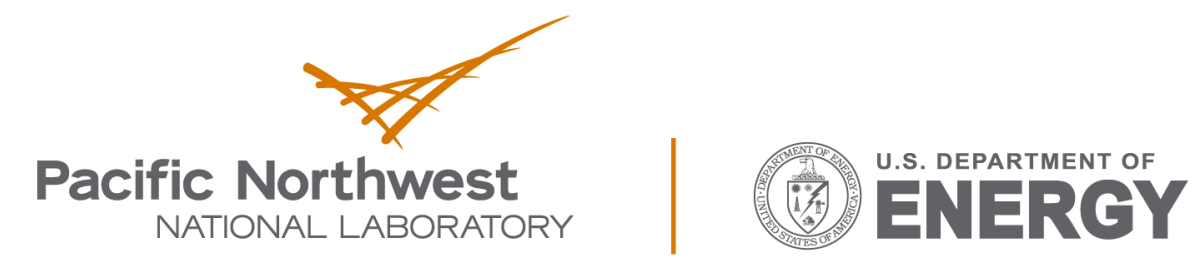

Proudly Operated by Battelle Since 1965

902 Battelle Boulevard

P.O. Box 999

Richland, WA 99352

1-888-375-PNNL (7665)

www.pnnl.gov 